\title{
A novel approach for health monitoring of earthen embankments
}

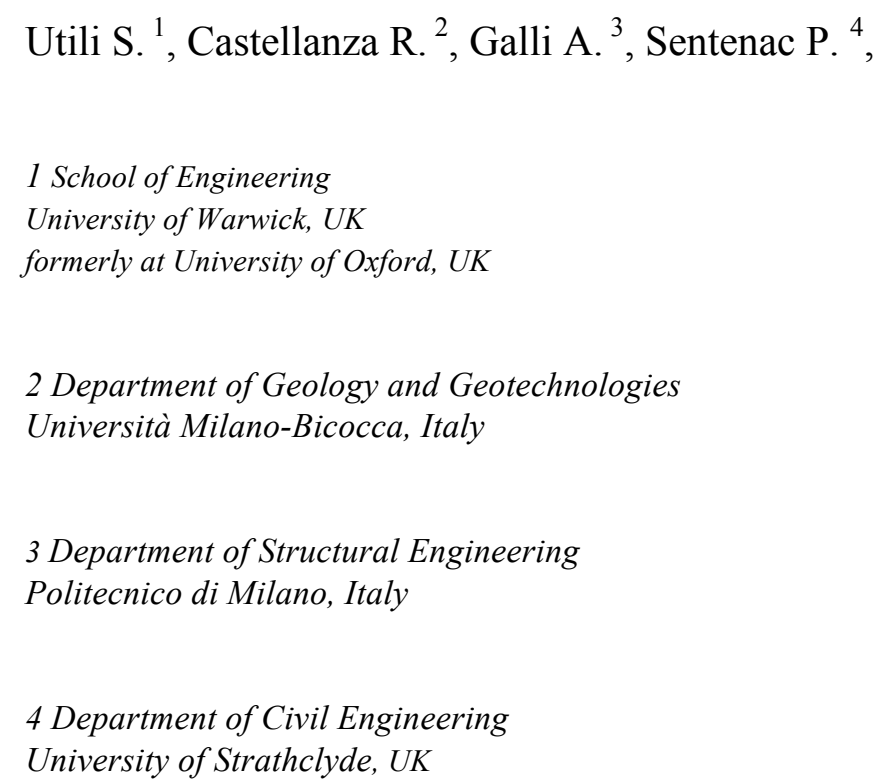

ABSTRACT. This paper introduces a novel modular approach for the monitoring of desiccation-induced deterioration in earthen embankments (levees), which are typically employed as flood defence structures. The approach is based on the use of a combination of geotechnical and non-invasive geophysical probes for the continuous monitoring of the water content in the ground. The level of accuracy of the monitoring is adaptable to the available financial resources.

The proposed methodology was used and validated on a recently built $2 \mathrm{~km}$ long river embankment in Galston (Scotland, UK). A suite of geotechnical probes was installed to monitor the seasonal variation of water content over a two-year period. Most devices were calibrated in-situ. A novel procedure to extrapolate the value of water content from the geotechnical and geophysical probes in any point of the embankment is illustrated.

Desiccation fissuring degrades the resistance of embankments against several failure mechanisms. An index of susceptibility is here proposed. The index is a useful tool to assess the health state of the structure and prioritise remedial interventions. 
38 KEY WORDS: embankments; earthfills; resilient infrastructures; geophysics; slope stability; desiccation fissuring. 39

40

41 
43 Earthen flood defence embankments also known as levees are long structures usually made of local material available at the construction site. In the UK, flood defence embankments are mainly made of cohesive soils: either clay or silt. Most of them were built before the development of modern soil mechanics in the eighteenth century (Charles, 2008). Due to their progressive aging, proper infrastructure condition assessment, based on sound engineering, is becoming increasingly important (Perry et al., 2001).

The formation of desiccation cracks in earthen embankments and tailing dams (Rodriguez et al., 2007) made of cohesive soils during dry seasons is detrimental to their stability. Desiccation is responsible for the onset of primary cracks which first appear at the surface, and then propagate downwards, and for so-called secondary and tertiary cracks (Konrad and Ayad, 1997). Desiccation induced failures are deemed to become increasingly important as progressively more extreme weather conditions are predicted by climatologists to take place worldwide (Milly et al, 2002). Allsop et al. (2007) provide a comprehensive list of the several failure modes that may take place in earthen embankments. Several potential failure mechanisms are negatively affected by the presence of desiccation cracks such as: deep rotational slides starting from the horizontal upper surface (Utili, 2013); shallow slides developing along the flanks (Aubeny and Lytton 2004; Zhang et al., 2005); erosion of the flanks by overtopping water (Wu et al., 2011) and/or wave action (D’Elisio, 2007); and internal erosion (Wan and Fell, 2004). In particular, the presence of cracks can substantially decrease the resistance of embankments with regard to overtopping and internal erosion which alone count for 34 and 28 percent respectively of all the embankment failures in the world (Wu et al., 2011).

Monitoring and condition assessment of flood defence embankments worldwide are 66 mainly carried out by visual inspections at set intervals (Morris et al., 2007; Andersen et al., 

guidelines exist to rate the health/deterioration of embankments on the basis of a prescribed set of visual features. Unfortunately, this type of assessment is purely qualitative and relies heavily on the level of training and experience of the inspection engineer. So, there is consensus among experts on the fact that although visual inspection provides valuable information, a meaningful and robust assessment of the fitness for purpose of earthen flood defence embankments cannot rely entirely on visual inspection (Allsop et al., 2007). On the other hand, intrusive tests (e.g. Cone Penetration test, piezocones, vane tests, inclinometers) are impractical for the monitoring of long structures like embankments given the necessity of performing tests in several locations to account for the typical high variability of the ground properties. The same applies to standard geotechnical laboratory tests which involve timeconsuming retrieval and transportation of samples to the laboratory.

In this paper, a cost effective approach employing a suite of geotechnical and geophysical probes is proposed for the long term monitoring of the variation of water content in the ground and of the liability to desiccation induced fissuring. The methodology is simple, modular (i.e. the level of sophistication/accuracy is a function of the financial resources available), and it can be readily implemented by the authorities in charge of the management of earthen flood defence embankments and tailing dams.

\section{Conceptual framework}

87 The methodology here proposed is based on the assumption that water content can be 88 selected as a direct indicator of the occurrence of extensive fissuring in the ground as 89 suggested by Dyer et al., (2009) and Tang et al., (2012). The authors are aware that a lot of research has been recently performed to successfully relate the onset of cracks to soil suction

91 (e.g. Shin and Santamarina, 2011; Munoz-Castelblanco et al., 2012b). However, as recently 
92 well illustrated by Costa et al., (2013), the formation and propagation of cracks in cohesive soils depends on several other factors too, such as the drying rate and the amount of fracture energy involved in the crack propagation. Considering flood defence embankments, loss of structural integrity (i.e. loss of the structure capacity to withstand the design hydraulic load) occurs when desiccation fissuring progresses to the extent that an interconnected network of cracks is formed rather than when surficial cracks first appear. Therefore the approximation introduced in relating the loss of structural integrity to a threshold value of suction appears no less important than the approximation introduced in relating it to a threshold value in terms of water content. Moreover, the cost of monitoring suction in a long embankment for an extended period of time is very significant with the extra burden of necessitating complex installation and maintenance procedures for the probes needed to measure suction. These reasons underpin the authors' choice of monitoring the ground water content.

The position of any point in a long linear structure like an embankment or tailing dam can be defined according to either a global Cartesian coordinate system $(\mathrm{X}, \mathrm{Y}, \mathrm{Z})$ or a local coordinate system defined at the level of the structure cross-sections. For sake of simplicity,

107 the following choice was made: a curvilinear global coordinate, $s$, running along the longitudinal direction of the structure which uniquely identifies the location of any cross section; a local Cartesian coordinate, $\mathrm{x}$, lying in the horizontal plane and perpendicular to the

110 s coordinate; and a vertical downward Cartesian coordinate, $z$, which can be thought of as

111 both a global and local coordinate. So, the water content, $w$, in a generic point of the earthen

112 structure is a function of these three spatial coordinates and of time: $w(x, s, z, t)$. A local 113 tangential coordinate $\mathrm{s}_{\mathrm{t}}$ was also defined as shown in Figure $1 \mathrm{~b}$. The procedure proposed to

114 determine the function $w=w(x, s, z, t)$ in the whole embankment is based on the following 115 actions: 
1) measurement of the water content profile along a vertical line $\mathrm{P}$ of coordinate $\mathrm{x}_{\mathrm{P}}, s_{\mathrm{P}}$ at any time and depth $w\left(x=x_{P}, s=s_{P}, z, t\right)=w_{P}(z, t)$;

2) measurements in some selected cross-sections, located at $s=s_{i}$ (herein the subscript $i$ is an integer identifying the embankment cross-section considered), at some discrete time points $t_{k}$ (herein the subscript $k$ is an integer identifying the time point considered), of the function $w\left(x, s=s_{i}, z, t=t_{k}\right)=w_{i ; k}(x, z)$;

3) measurement by geophysical techniques of the water content at predefined time points, $t_{k}$, along the entire embankment (i.e. for any value of $s$ );

4) evaluation by extrapolation of the water content in any point at any time: $w(x, s, z, t)$.

Once the water content function $w(x, s, z, t)$ is determined, an index quantifying the susceptibility of any cross-section of the embankment to desiccation fissuring can be defined and a map of susceptibility can be generated to identify the most critical zones of the structure (see section 8). The map is useful to set priorities for intervention in the zones requiring remedial actions.

\section{Description of the site}

132 In 2007, the construction of an earthen flood defence embankment enclosing a floodplain

133 along the river Irvine to drain excess waters from the river during floods was completed in

134 Galston (Scotland, UK). The embankment is made of an uppermost layer $(5-10 \mathrm{~cm})$ of a sandy topsoil below which lies a core of glacial till containing several boulders (Figure 1).

136 Grass roots do not extend beyond the topsoil. A typical cross- section is sketched in Figure

137 1b. Although the inclination of the flanks is rather uniform, the size of the flanks and of the 138 upper surface vary quite substantially along the longitudinal direction giving rise to a non- 
139 negligible spatial variation of the geometry of the cross-sections which may have 140 consequences in terms of the spatial variation of the water content in the ground (see sections 1416 and 7).

142

149 A number of standard geotechnical tests were carried out to characterise the ground 150 properties: measurements of gravimetric moisture content, void ratio, particle size 151 distribution and Atterberg limits were taken. The grain size distribution of both the top soil 152 and the glacial till was determined according to ASTM E11 (see Figure 2).

Figure 1. a) Plan view of the monitored embankment; b) typical embankment cross section and system of coordinates adopted in the paper.

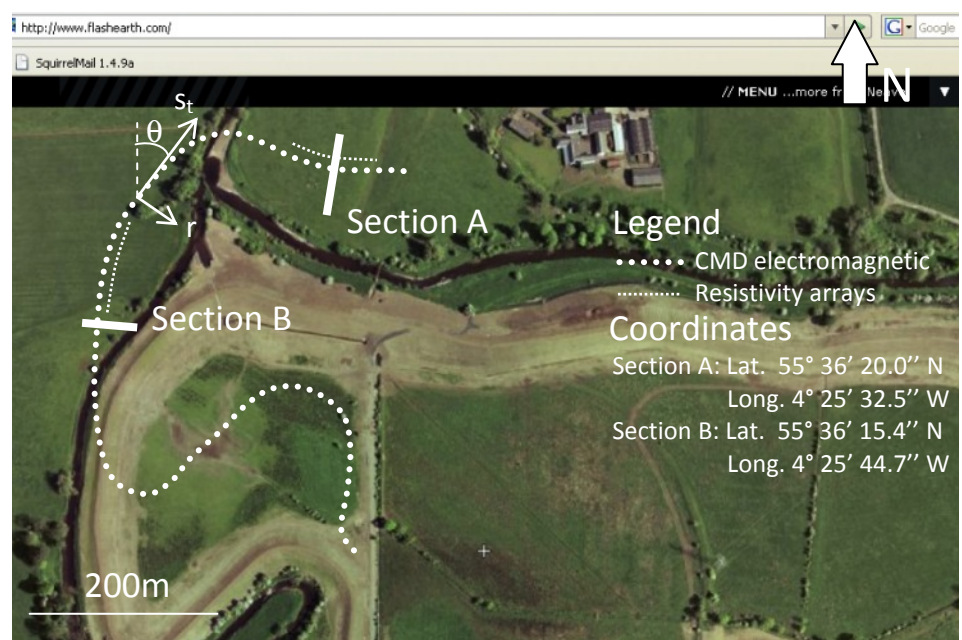

a)

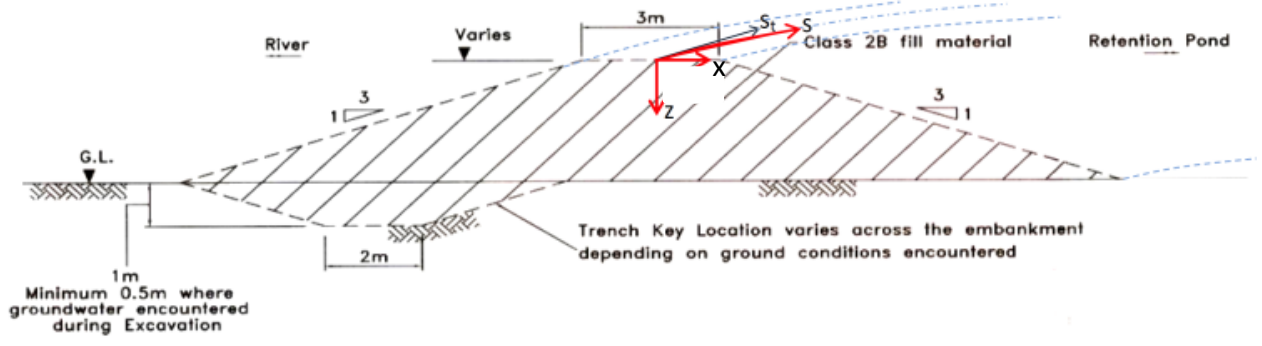

b) 


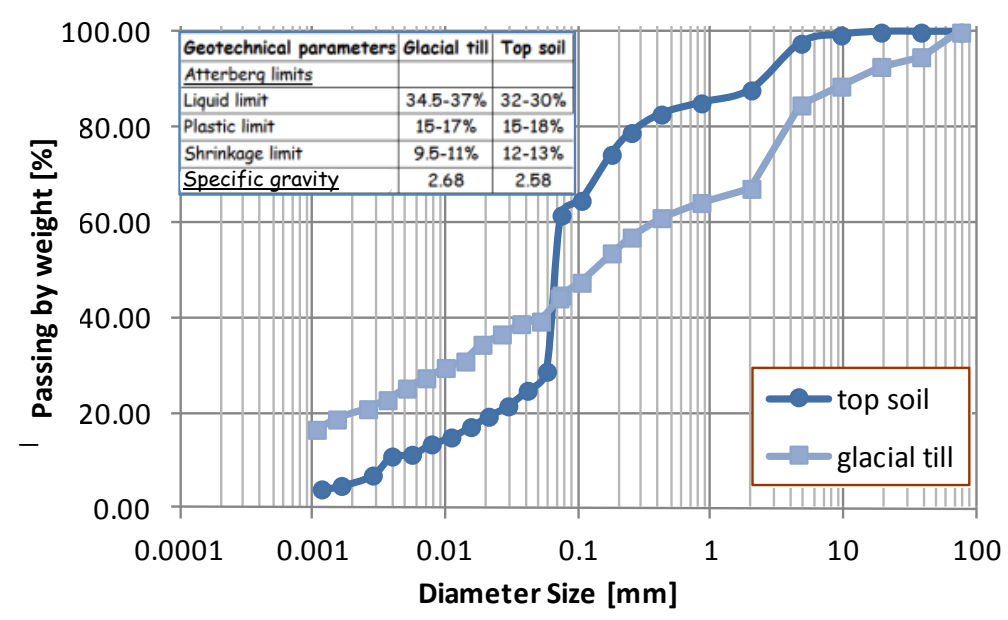

\section{Monitoring system}

In the following, the main geotechnical and geophysical measurements of the monitoring system are described. The main technical features of all the probes employed in the monitoring programme (e.g. manufacturer, accuracy, operational range, etc.) are listed in Table 1.

\subsection{Measurement of the water content along the selected vertical $P$}

In Figure 3b, the vertical line P is plotted with the label PR2_E2. A data-logger, reading data at an hourly frequency was installed into a bespoke metallic fence close to the vertical line $\mathrm{P}$ (see Figure 3c). As schematically shown in Figure $3 a$ and $b$, the following devices were connected to the data-logger:

a) a theta probe (THP) made of four metal rods to be inserted in the ground to measure its water content at a depth of $25 \mathrm{~cm}$. Special care was taken to avoid the formation of any air gaps between the prongs of the probe and the surrounding soil by prefilling the augered holes hosting the probes with a slurry and pushing the probe into undisturbed soil well beyond the hole bottom. The device takes a measurement of the relative 

permittivity (also commonly called dielectric constant) of the ground which is then

173 converted into gravimetric water content;

174 b) an equitensiometer (EQ) to measure suction up to a maximum value of $1000 \mathrm{kPa}$ at 175 the same depth of $25 \mathrm{~cm}$. This device consists of theta probe pins embedded into a $176 \quad$ porous matric;

177 c) a portable profile probe (PR), which is based on time domain reflectometry, to 178 measure the water content at six different depths from the ground surface $(10,20,30$, $179 \quad 40,60$ and $100 \mathrm{~cm})$;

180 d) two temperature probes inserted at 25 and $40 \mathrm{~cm}$ of depth in the ground.

\subsection{Measurement of the water content at cross-section $A$ and $B$}

183 To evaluate the water content in the ground up to 1 meter of depth, several access tubes were drilled into two cross-sections ( $\mathrm{A}$ and $\mathrm{B}$ in Figure $3 \mathrm{a}$ and $\mathrm{b}$ ) with the property of being perpendicular to each other to better account for the influence of topographical orientation on the measured water content (see section 7). Special care was taken to avoid the formation of

187 any air gaps between the tubes where the PR was inserted and the surrounding soil. Two different instruments were employed:

189 a) the PR, already described in the previous section, to measure the ground water content

b) a portable diviner (D) (see Sentek Diviner 2000 in table 1) to measure the ground water content along various vertical lines every $10 \mathrm{~cm}$ from ground level down to 1.6 and 5 for the diviner (labeled DV_xx). In section B there were 12 measuring points: 6 for the profile probe and 6 for the diviner. Some of the access tubes for the profile probe and the 
197 diviner were laid down so as to be aligned along the longitudinal direction of the

198 embankment in order to perform a cross-comparison between them as it will be illustrated in

199 section 5 (see Figure 3a and b).

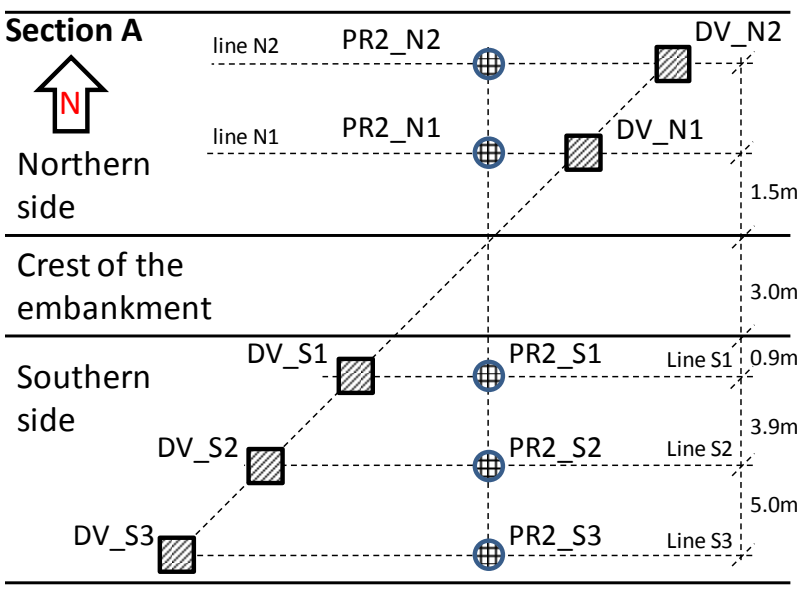

a)

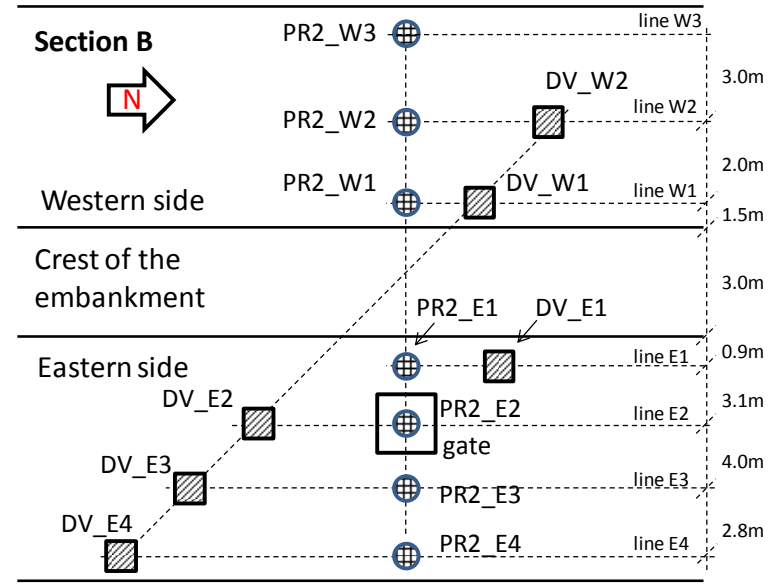

b)

202

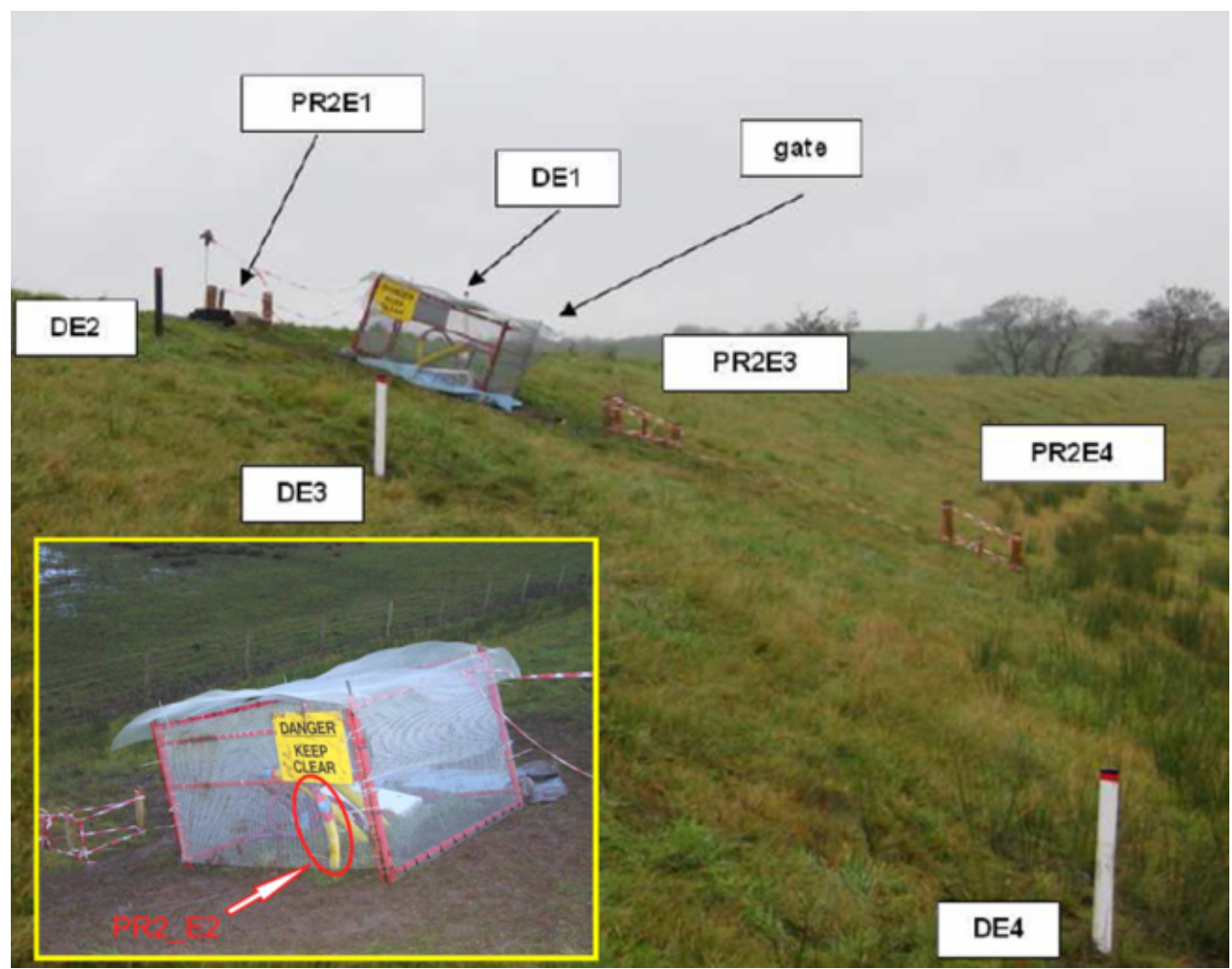

c)

Figure 3. Position of the access tubes for the profile probe (PR2) and the diviner (D): (a-b) plan view of sections $A$ and $B$, respectively; (c) view of cross section $B$ from the Eastern side. 
210 humidity, temperature and wind speed over the two year period of monitoring.

212 Table 1. Main technical features of the probes employed in the monitoring.

\begin{tabular}{|c|c|c|c|}
\hline Device & Product name & Manufacturer & Accuracy and operational range \\
\hline Equitensiometer & EQ2 & $\begin{array}{l}\text { Delta-T Devices Ltd } \\
\text { United Kingdom } \\
\text { www.delta-t.co.uk/ } \\
\end{array}$ & $\begin{array}{l} \pm 10 \mathrm{kPa} \text { in the range from } 0 \text { to }-100 \mathrm{kPa}, \\
\pm 5 \% \text { in the range from }-100 \text { to }-1000 \mathrm{kPa} \text {. }\end{array}$ \\
\hline Theta probe & THP & $\begin{array}{l}\text { Delta-T Devices Ltd } \\
\text { United Kingdom } \\
\text { www.delta-t.co.uk/ } \\
\end{array}$ & $\begin{array}{l}\text { after calibration to a specific soil type: } \\
\pm 0.01 \mathrm{~m}^{3} \cdot \mathrm{m}^{-3}, \text { in the range from } 0 \text { to } 0.4 \mathrm{~m}^{3} \cdot \mathrm{m}^{-3} \\
\text { with temperature from }-20 \text { to } 40^{\circ} \mathrm{C},\end{array}$ \\
\hline Profile probe & PR2 & $\begin{array}{l}\text { Delta-T Devices Ltd } \\
\text { United Kingdom } \\
\text { www.delta-t.co.uk/ } \\
\end{array}$ & $\begin{array}{l}\text { after calibration to a specific soil type: } \\
\pm 0.04 \mathrm{~m}^{3} \cdot \mathrm{m}^{-3}, \text { in the range } 0 \text { to } 0.4 \mathrm{~m}^{3} \cdot \mathrm{m}^{-3} \\
\text { reduced accuracy from } 0.4 \text { to } 1 \mathrm{~m}^{3} \cdot \mathrm{m}^{-3}\end{array}$ \\
\hline Diviner & Diviner 2000 & $\begin{array}{l}\text { Sentek Pty Ltd } \\
\text { Australia } \\
\text { www.sentek.com.au } \\
\end{array}$ & $+/-0.003 \%$ vol in the range from -20 to $+75^{\circ} \mathrm{C}$ \\
\hline Weather station & iMETOS pro & $\begin{array}{l}\text { Pessl Intruments } \\
\text { http://metos.at/joomla/page/ }\end{array}$ & $\begin{array}{l}\text { temperature: }+/-0.1^{\circ} \mathrm{C} \text { in the range }-40^{\circ} \text { to }+60^{\circ} \\
\text { relative humidity: } 1 \% \text { in the range } 0 \text { to } 100 \% \\
\text { wind speed: } 0.3 \mathrm{~m} / \mathrm{s} \text { in the range } 0 \text { to } 60 \mathrm{~m} / \mathrm{s} \\
\text { precipitation: }+/-0.1 \mathrm{~mm}\end{array}$ \\
\hline $\begin{array}{l}\text { Electromagnetic } \\
\text { probe }\end{array}$ & CMD-2 & $\begin{array}{l}\text { Gf Instruments } \\
\text { Czech Republic } \\
\text { http://www.gfinstruments.cz }\end{array}$ & $\begin{array}{l} \pm 4 \% \text { at } 50 \mathrm{mS} / \mathrm{m} \\
\text { Operating temperature: }-10{ }^{\circ} \mathrm{C} \text { to }+50{ }^{\circ} \mathrm{C} \\
\text { Maximum sampling rate: } 10 \mathrm{~Hz}\end{array}$ \\
\hline
\end{tabular}

213

\section{$214 \quad 4.3$ Geophysical measurements}

215 Electromagnetic surveys present the advantage of being non-intrusive and quick to be carried

216 out. Electromagnetic probes can measure the electrical conductivity of the ground. The

217 CMD-2 probe from Gf Instruments (see Table 1) was chosen for being a relatively cheap

218 device and simple to be used, i.e. without requiring a specific training. In Gf Instruments

219 (2011) the working principles of the device are illustrated. Measurements were taken by an

220 operator walking on the horizontal upper surface of the embankment along the longitudinal

221 direction at a constant pace of $5 \mathrm{~km} / \mathrm{h}$, holding the CMD-2 approximately $1 \mathrm{~m}$ above ground

222 with the device oriented perpendicular to the longitudinal direction so that the

223 electromagnetic flow-lines always lie in the plane perpendicular to the longitudinal direction

224 (i.e. the plane of the embankment cross-section). 
Electrical resistivity tomography (ERT) is also a well-established geophysical technique that is increasingly employed to measure electrical conductivity at the ground surface

227 (Munoz-Castelblanco et al., 2012a). Nowadays, 3D maps of in-situ water content can be generated from ground resistivity measurements, as shown in (De Vita et al., 2012; Di Maio and Piegari, 2011), once appropriate correlations between ground resistivity and in-situ water content have been established. The potential for obtaining 3D maps of water content makes ERT look like a very attractive tool for the monitoring of embankments. However, ERT appears to be impractical for the continuous monitoring of an extended structure over long timespans since it requires operators possessing the specialist skills to install the electrodes of

234 the devices in the ground and operate them. For this reason, in order to take geophysical measurements of electrical conductivity in the embankment (see section 7.2) we chose to use electromagnetic probes instead. Nevertheless, in the authors' opinion, ERT could still be beneficially employed in the zones of the embankment identified as critical by the integrated geotechnical/geophysical approach here proposed. In fact, ERT is useful to investigate in great detail the state of fissuring of the ground in zones of limited extent.

\section{Calibration of the geotechnical suite}

242 A key point of any monitoring system is the proper calibration of all the employed devices. Regarding the calibration exercise undertaken, only the glacial till is of interest since the thickness of the top soil in the embankment flanks, where all the measurements were taken, is approach was adopted which is detailed in the following. 


\subsection{Direct calibration of the theta probe}

249 The calibration curve for the theta probe (THP) was taken from Zielinski, (2009) (see Figure

250 4) who calibrated the THP using samples of till retrieved from the same quarry (Hallyards, 251 Scotland, UK) from which the till of our monitored embankment was extracted. The till was 252 retrieved from the quarry at five different known water contents and compacted into five 253 cylindrical containers with the same compaction effort as in the monitored embankment, i.e. 254 relative compaction of $95 \%$ with compaction control performed according to the 255 Specification for Highway Works: Earthworks, Series 6000 (Highways Agency, 2006). Given 256 the high level of compaction and the non-swelling nature of this glacial till, the variations of 257 dry unit weight in the embankment over time and space occurring for the range of measured 258 in-situ water contents can be considered negligible (less than $+/-5 \%$ ). Hence, we transformed 259 the volumetric water contents measured by the geotechnical probes (profile probe, diviner, 260 etc.) into gravimetric water contents assuming the dry unit weight of the till at its optimal 261 water content, i.e. a maximum dry unit weight of $19.1 \mathrm{kN} / \mathrm{m}^{3}$. This value was obtained as 262 average of 7 measurements performed in the laboratory on undisturbed U-38 samples 263 retrieved from the embankment. This value turned out to be almost identical to the value measured by (Zielienski, 2011) on a small scale embankment built from the same glacial till reconstituted in the laboratory.

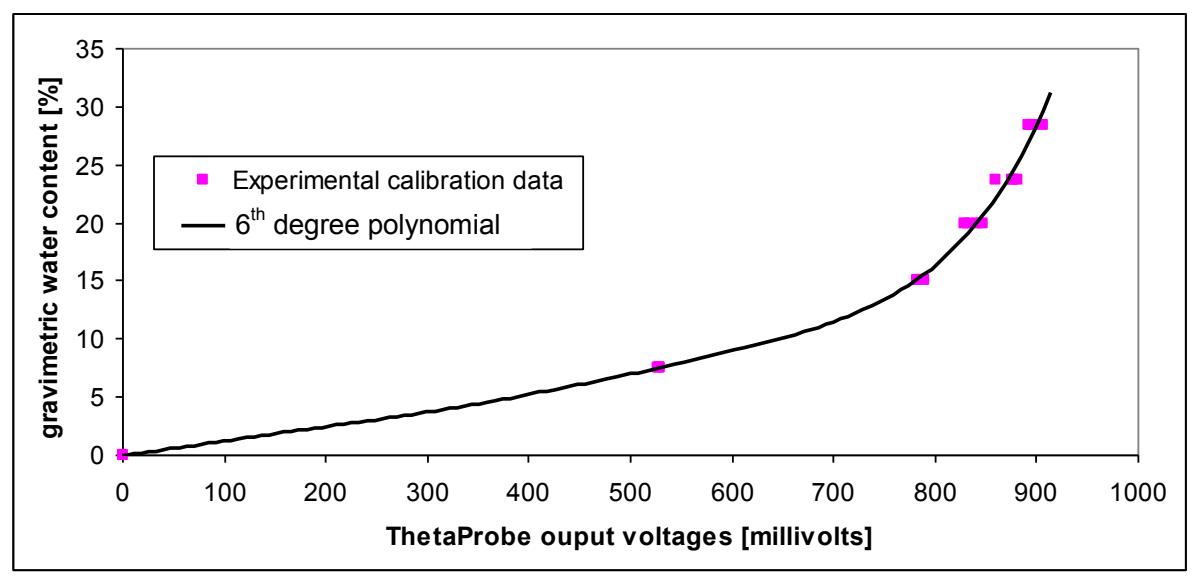




\section{$269 \quad 5.2$ Indirect calibration of the profile probe}

270 The calibration of the profile probe (PR) was obtained by comparing the raw data in 271 millivolts obtained by the PR located at the gate in section B (PR2_E2 in Figure 3) at 20 and $27230 \mathrm{~cm}$ depth with the measurements of the theta probe (THP) in the same location $(20 \mathrm{~cm}$ 273 longitudinally away from the PR2_E2 in Figure 3) at $25 \mathrm{~cm}$ depth for a 4 month period. Data 274 were recorded every 4 hours. A strong similarity between the trends of the readings of the 275 two probes plotted in Figure 5 was observed. Since the two devices measure the water 276 content of the same portion of soil, a calibration procedure, based on the visual match of the 277 curves, was adopted: the scale of the ordinate axis of the THP readings (expressed in $\mathrm{mV}$ ) 278 was varied until it satisfactorily matched the average (not reported in the figure to avoid 279 cluttering) of the two measurements at 20 and $30 \mathrm{~cm}$ depth obtained by the THP. The

280 resulting linear relationship between the values measured by the PR and the values measured 281 by the THP is shown in Figure 5. This relationship was used to convert the readings of the PR 282 into equivalent milliVolt units measured by the THP, and then they were in turn transformed 283 into gravimetric water content employing the calibration curve of the THP (Figure 4). 


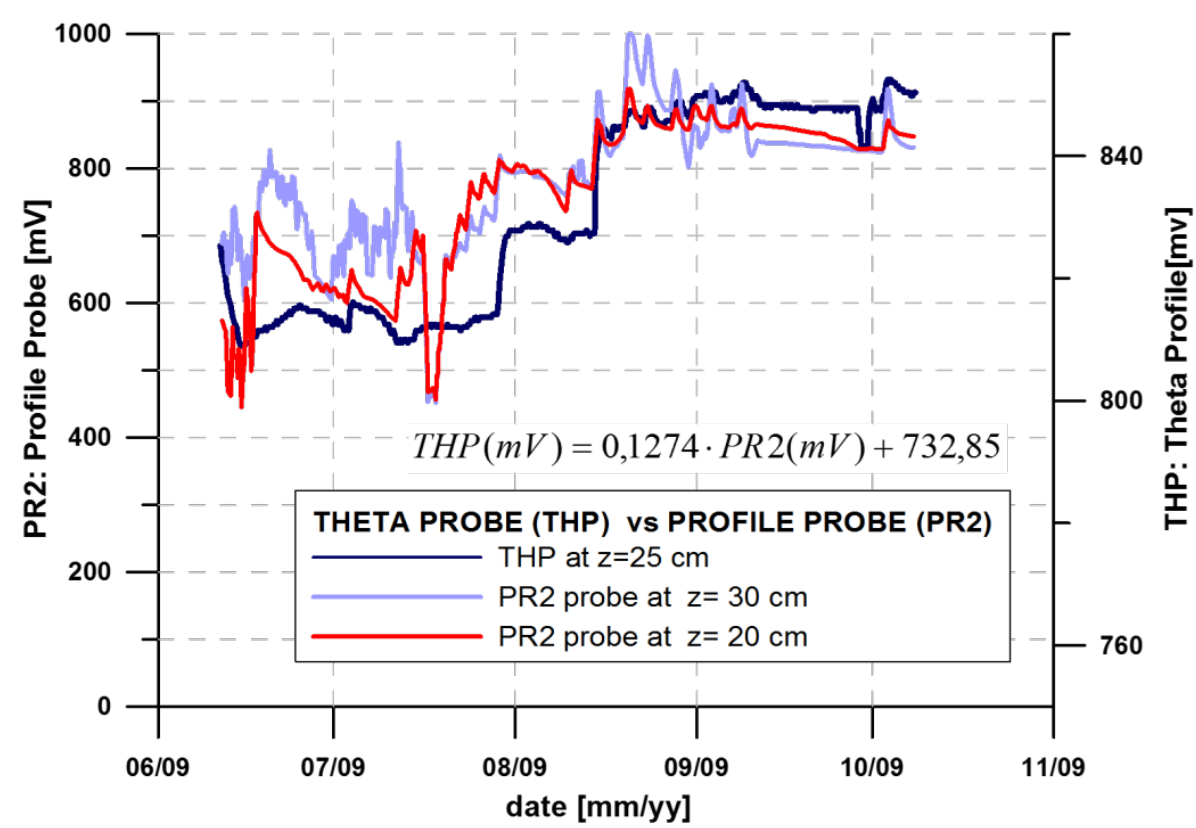

Figure 5. Calibration of the profile probe: measurements by the theta probe and the profile probe taken at the same location, PR2_E2 (see Figure 3).

\subsection{Indirect calibration of the diviner}

290 Following the same approach described in the previous section, indirect calibration of the diviner (D) was performed by varying the scale of the frequencies measured by the D until a satisfactory match with the water content profile measured by the PR in the corresponding access tube was obtained. The corresponding PR access tube is the one aligned with the D tube in the longitudinal direction (e.g. DV_S3 and PR2_S3, see Figure 3a). In Figure 6a, two of the performed calibrations are shown. The curve shown in Figure $6 \mathrm{~b}$ was obtained by repeating this procedure for all the monitoring points of the $\mathrm{D}$ in the time period considered. correlation, errors of measurement could be amplified. Hence, in order to check the amount of error amplification, direct measurements of the gravimetric water content were obtained

300 via small in-situ samples taken in several points of the embankment on the same day (see the triangles in Figure 6a). Looking at Figure 6a, a good agreement between the values of water 

emerges so that it can be concluded that error propagation is within acceptable limits. indirectly calibrated in-situ. Conversely, direct calibration of the PR and D would require retrieving large volumes of soil, to avoid the influence of boundary effects, at predefined water contents to the laboratory.

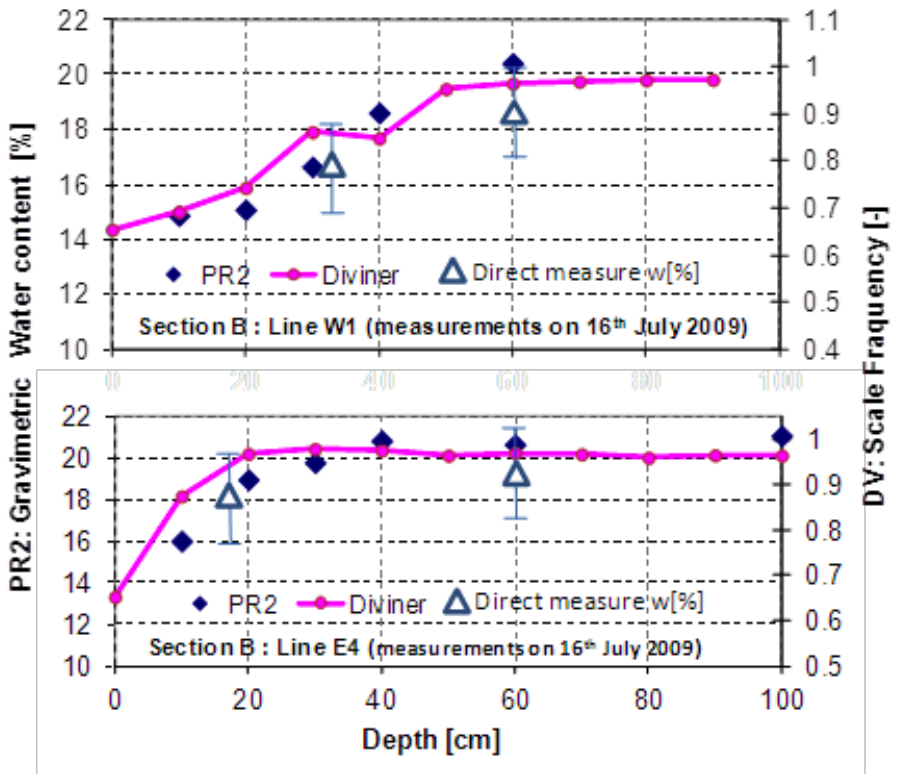

a)

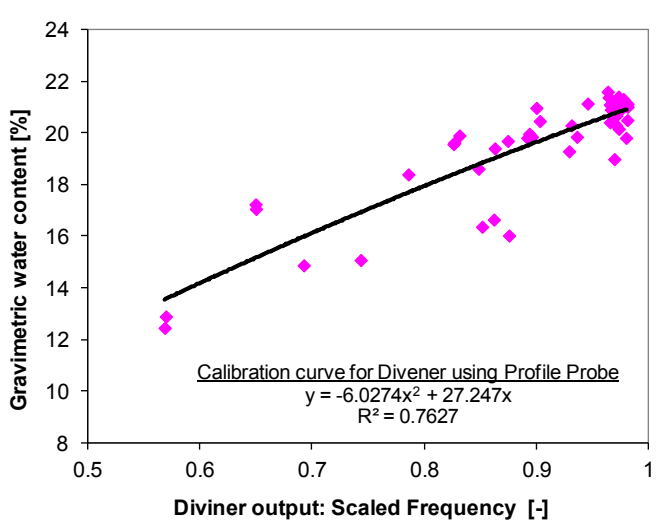

b)

Figure 6. Calibration of the diviner by comparison with the measurements of the profile probe: a) examples of cross comparisons for measurements taken in access tubes lying along the longitudinal line W1 and E4 (see Fig. 3 for location of the lines). The triangles with their error bar indicate the values of water content obtained via direct measurement. b) Obtained calibration curve for the diviner. 


\section{Monitored data}

319 In this section data relative to rainfalls, wind speed, relative humidity, air and ground temperature recorded by the weather station installed near to the embankment are analysed and compared with the ground water content recorded by the geotechnical suite in crosssections A and B. The purpose of this analysis was first to establish the variation in time and space of the water content and secondly to identify correlations between weather variables and ground water content in order to separate out the variables significantly affecting the water content from the ones with a marginal influence which therefore can be discarded from the monitoring programme.

In principle it would be possible to calculate the effective amount of rainfall infiltrating in the ground from the calculation of evapotranspiration rates and the measurement or calculation of the amount of water runoff (Smethurst et al., 2012; Xu and Sing, 2001). However, the amount of runoff is likely to depend strongly on the inclination of the embankment flanks which varies locally and to a lesser extent on to the local vegetation cover. Moreover, a reliable estimate for a long linear structure with varying cross-section geometries would require several points of measurement. This is against the overall philosophy of the proposed methodology which aims to be as practical and simple as possible. Hence, we sought a relationship between in-situ water content and total precipitated rainfall. The latter can be measured directly by a nearby weather station. Furthermore, in the UK at least, weather stations can be found in several localities so that often there will be no need to install a new station in the site of interest. In summary, on one hand using total rainfall makes the correlation with the in-situ water content weaker because of the extra approximation of disregarding the variation of effective rainfall in the ground due to local

341 lithological and geometrical variations; however on the other hand, it is far more desirable for 
the authorities in charge of the monitoring system since total rainfall is much easier to be ascertained.

\subsection{Continuous measurements of water content profiles}

346 Data were recorded over a 2 year period. Here, only an extract of two significant periods is

347 provided to illustrate the seasonal trends of desiccation and wetting of the embankment. The 348 most significant seasons are summer (see Figure 7) and winter (see Figure 9). In Figure 7a, 349 the ground water content profile is plotted together with the recorded daily rainfall 350 precipitation. Precipitations larger than about $5 \mathrm{~mm} /$ day or reaching $5 \mathrm{~mm}$ over a period of 351 consecutive daily rainfalls lead to noticeable increases of water content apparent in the spikes

352 of the curves relative to the water contents measured at 10 and $20 \mathrm{~cm}$ depth. No significant variations of water content were ever recorded at depths larger than $60 \mathrm{~cm}$.

354 In the upper part of Figure $7 \mathrm{a}$, the suction measured by the EQ2 at $25 \mathrm{~cm}$ depth is plotted. It emerges that the suction is well related to the rainfall records as well as to the variation of water content. After several consecutive days of rainfall in late August, the suction vanished to 0 for the entire winter period. For this reason, the variation of suction was not reported in Figure $9 \mathrm{~b}$ relative to the winter period. The THP measured water content at the same depth of the suction measurements of the EQ in a point $15 \mathrm{~cm}$ away along the horizontal direction so that an in-situ suction-water characteristic curve (SWCC) for the

361 considered point (PR2_E2) can be obtained (curve C in Figure 8). Zielienski et al. (2011)

362 measured in the laboratory the SWCC of this glacial till with different techniques (curves A in Figure 8) and the SWCC (curve B in Figure 8) in a small scale embankment made of the same material. In Figure 8, all these curves are plotted. Comparing the curves, it emerges that the values of in-situ suction measured by the EQ lie close to the SWCC curves obtained in 
the laboratory and also that the boundaries of the hysteresis cycles are close. This result is

367 quite remarkable.

368 Examining the recorded temperatures of the air and ground, a clear correlation between 369 the two is found: in Figure $7 \mathrm{~b}$ the average between the maximum and minimum daily air 370 temperature turns out to be very close to the ground temperature at $10 \mathrm{~cm}$ depth. Relative 371 humidity and wind speed were rather constant during the monitored period (see Figure 7c).

372
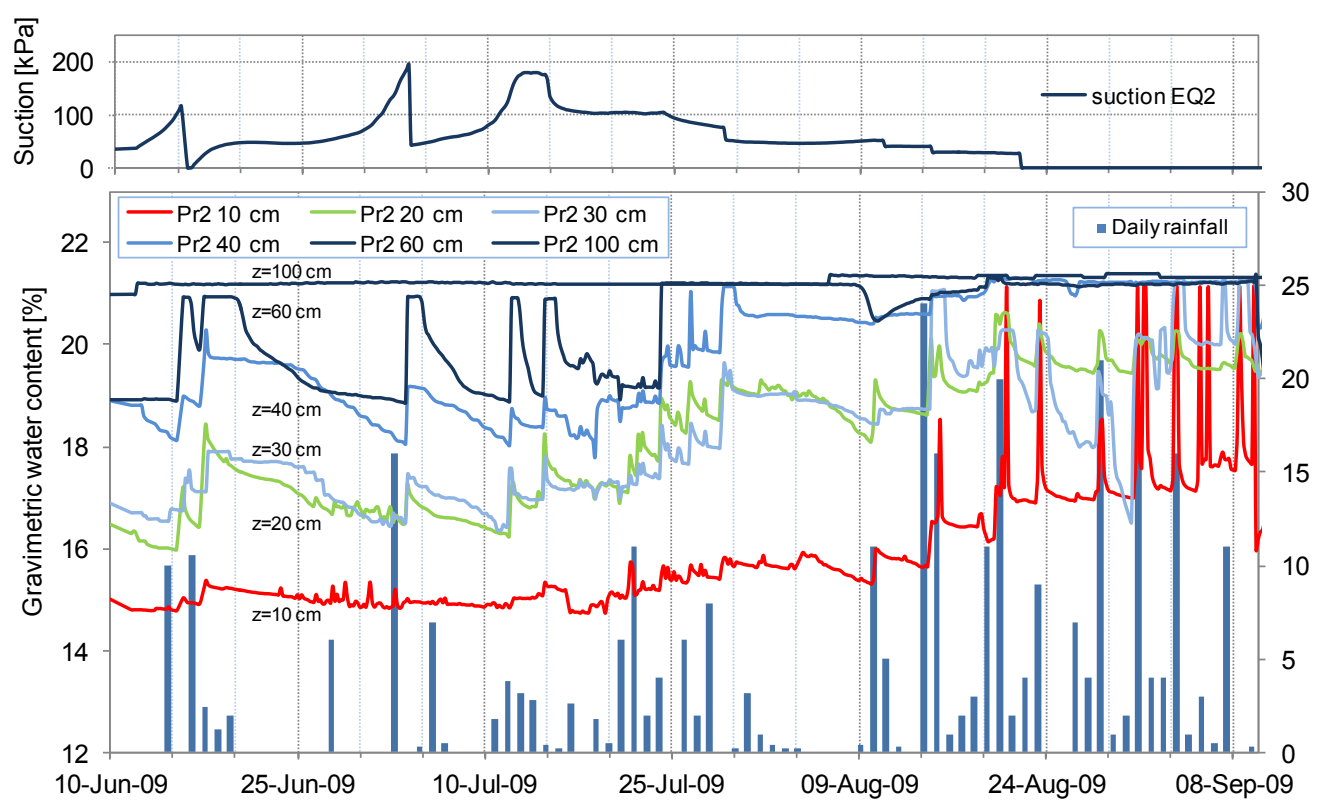

a)

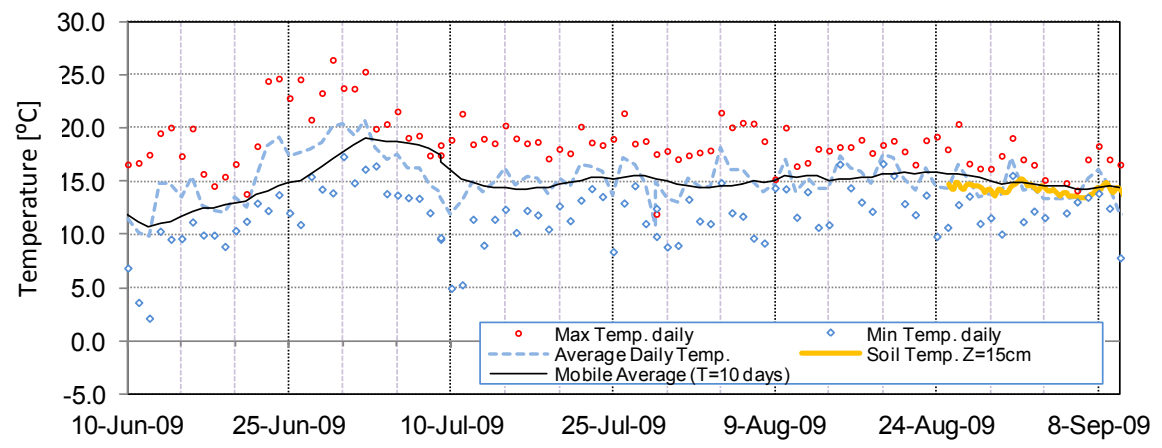



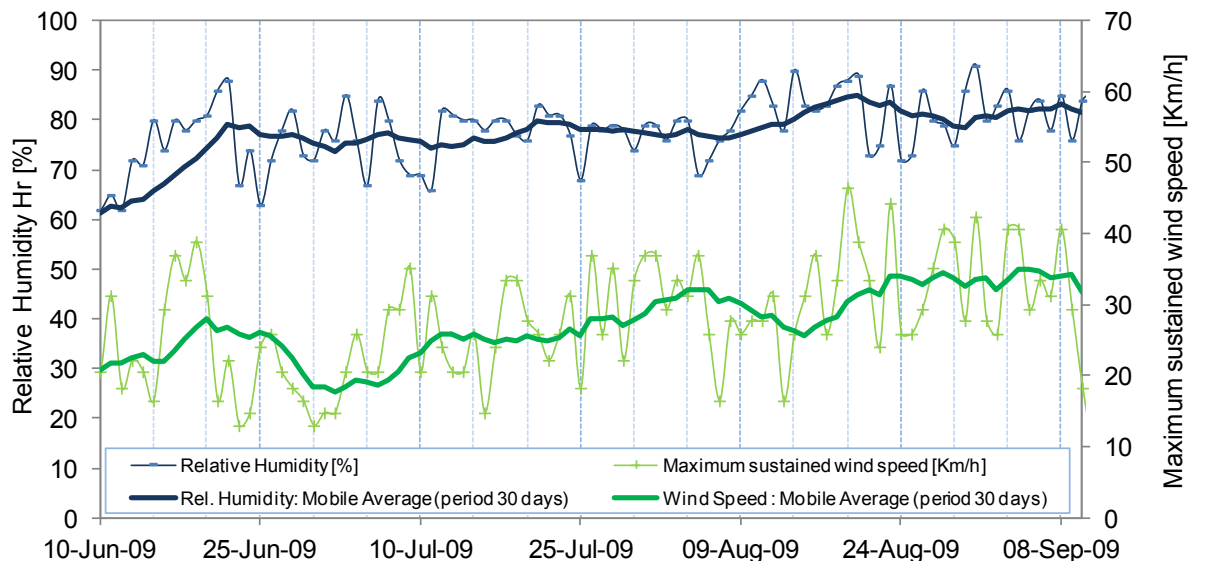

c)

379 Figure 7. Summer 2009 (section B): a) evolution of the gravimetric water content, suction and rainfall record; 380 b) average between the maximum and minimum daily air temperature (grey line) and ground temperature 381 measured at $10 \mathrm{~cm}$ depth; c) relative humidity and wind speed: the thin line follows the daily variation whereas 382 the thick line is the mobile average over 10 days. 


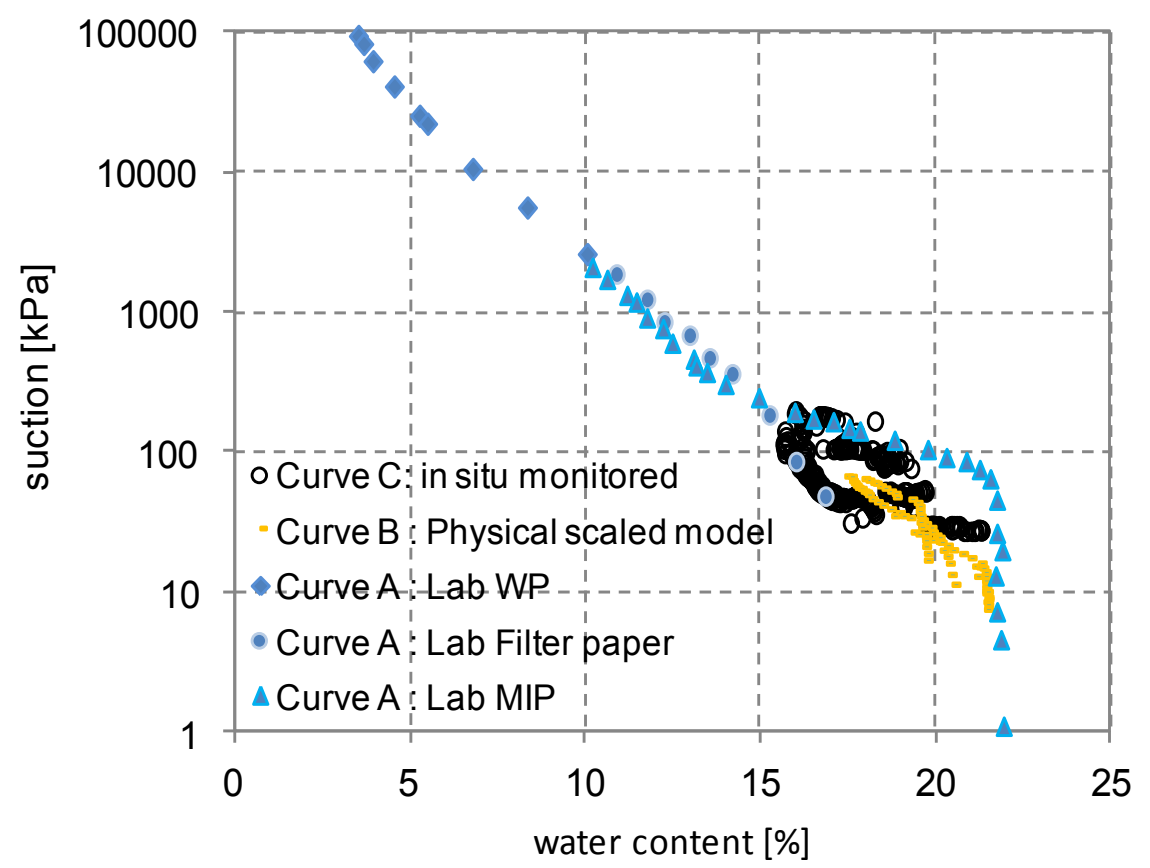

Figure 8. Comparison of in situ suction - water characteristic curve (SWCC) derived from measurements taken by the THP and the EQ at $25 \mathrm{~cm}$ depth (Curve C) with the $S W C C$ determined from reconstituted samples (Curves A, after Zielinski et al. (2011)) and in a small scale embankment model (Curve B, Zielinski et al. (2011)).

In winter (see Figure 9), higher precipitations take place leading to significantly larger quick increases of the ground water content, in particular at shallow depths $(10 \mathrm{~cm})$. The same remarks as for the summer period can be made with the exception of the wind speed which varies significantly more than during the summer period.

From the monitored data, it can be concluded that the ground water content is highly sensitive to the amount of total precipitation and to the length of the dry periods whereas no significant correlation to relative humidity or to the variation of wind speed was found. These observations lead to state that in principle it is possible to estimate the water content in a cross-section, and in turn the cross-section susceptibility to desiccation fissuring (see section

399 8), from knowledge of both ground water content at the initial time of monitoring and 400 historical rainfall records. Given the limited resources available in this project, continuous 401 measurements in time are available only in 1 section of the embankment which is too little to 402 validate a reliable correlation between historical rainfall records and water content. However 
in light of the results obtained here, we suggest that if a sufficient number of sections are

404 instrumented, a reliable correlation may be established so that meteorological data (especially

405 rainfall records) could be used to infer the amount of water content along the entire

406 embankment at any time according to the methodology presented in the next section (section

407 7) and to monitor susceptibility of the structure to desiccation fissuring (as expounded in section 8). This methodology would have the advantage of not requiring periodic walk-over surveys, but only the presence of a weather station nearby the structure.

410

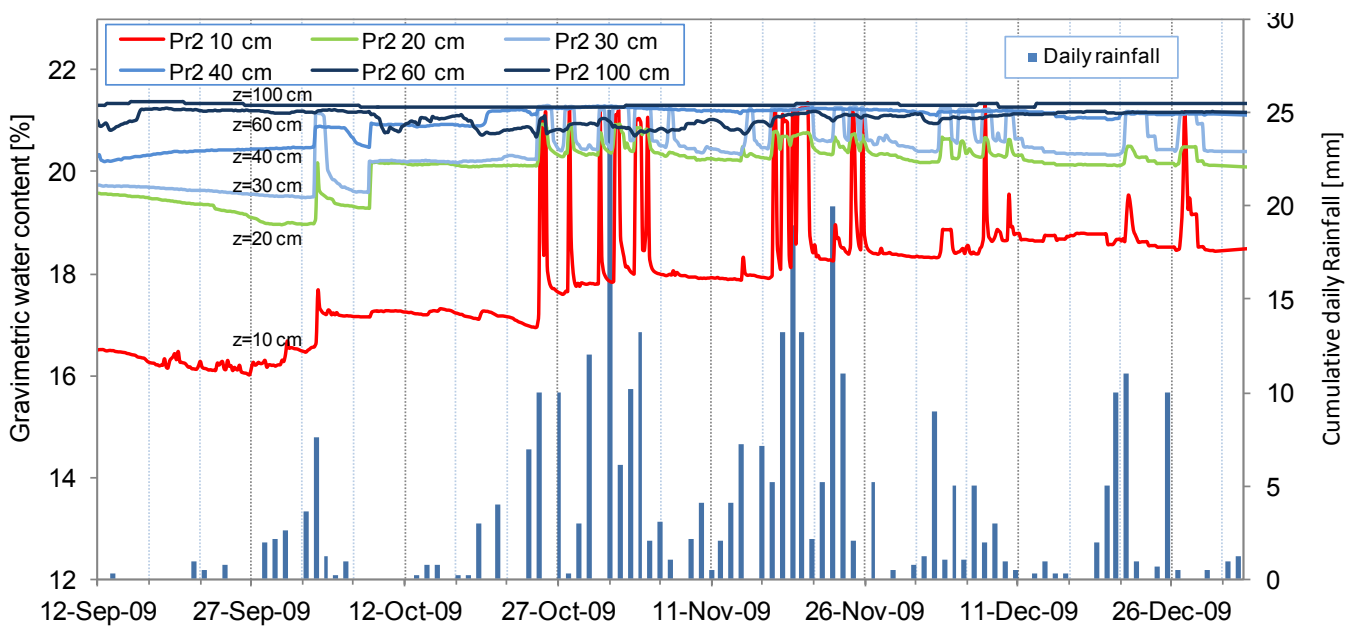

412 


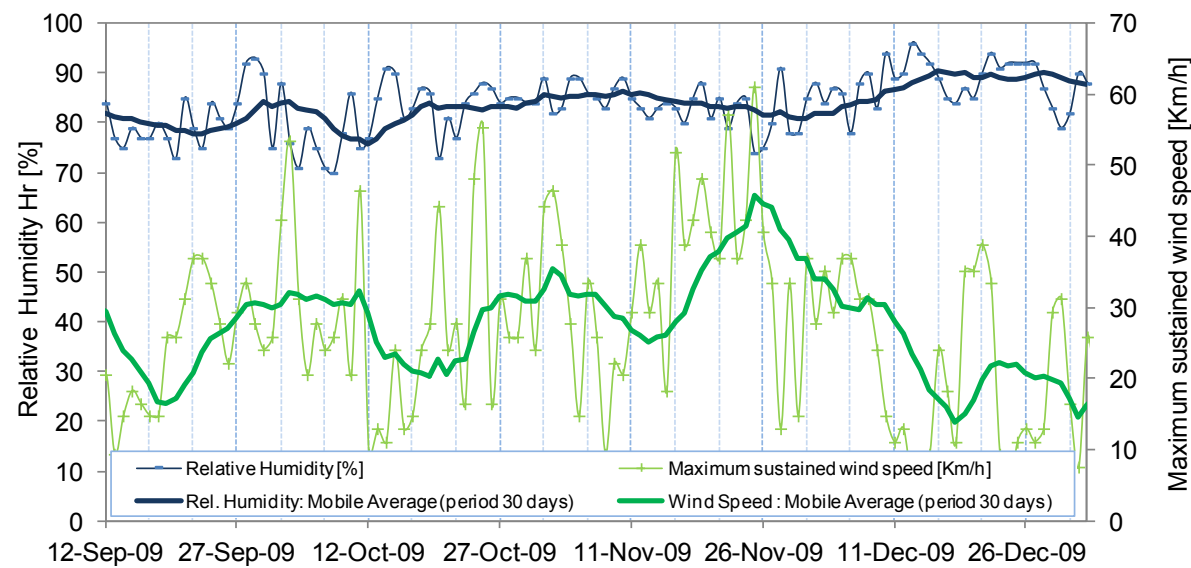

Figure 9. Winter 2009 (cross-section B): a) evolution of the gravimetric water content and rainfall record; $b$ ) average between the maximum and minimum daily air temperature (grey line) and ground temperature measured at $10 \mathrm{~cm}$ depth; c) relative humidity and wind speed: the thin line follows the daily variation whereas the thick line is the mobile average over 10 days.

\subsection{Time discrete measurements of water content profiles}

423 To evaluate $w_{i ; k}=w(x, z)=w\left(x, s=s_{i}, z, t=t_{k}\right)$, measurements were taken from the profile probe (PR) and the diviner (D) up to a depth of $1 \mathrm{~m}$ (see Figure 10). In Figure 11a and Figure

$42511 \mathrm{~b}$, the evolution of the water content over time is plotted for section A and B respectively.

426 These figures were obtained by interpolating in space the values of water content measured

427 from the locations of the monitoring points (see Figure 3). The analyzed domain consists of 428 the uppermost $1 \mathrm{~m}$ of the cross-sections since no significant variations of water content were ever observed at larger depths (see Figure 7 and Figure 9). To generate the plotted contours 430 of water content, first a mesh was created whose nodes coincide with the locations of the 431 readings taken from the $\mathrm{PR}$ and the $\mathrm{D}$, then a post-processing FEM software, called GID 432 (GID, 2014), was employed to interpolate the values along the $\mathrm{x}$ and $\mathrm{z}$ coordinates. The 433 interpolation was repeated for measurements taken at different times (see Figure 11). From 434 these data it emerges that the water content varies significantly between the two sections. The 435 dependence of the water content on the geometrical alignment of the cross-sections, has been 
436 accounted for in deriving the function $w(x, s, z, t)$ as it will be illustrated in the next

437 paragraph.

438

439

440

441

442

443

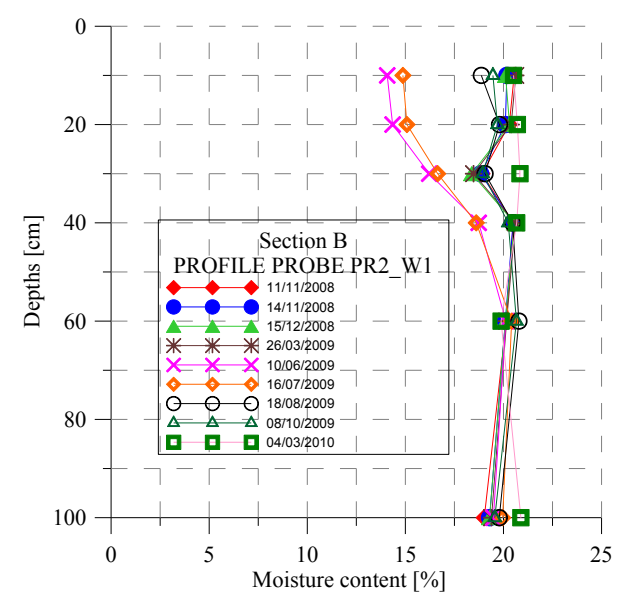

a)

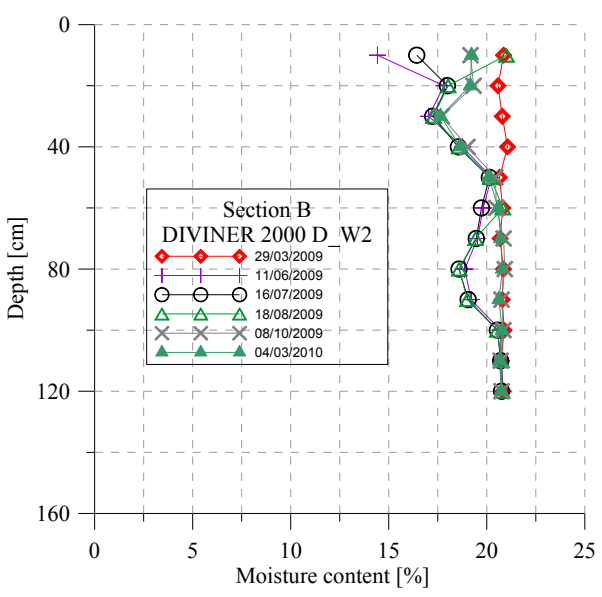

b)

Figure 10. Examples of profiles of the water content at different times in cross-section B: a) obtained by the profile probe; b) obtained by the diviner.

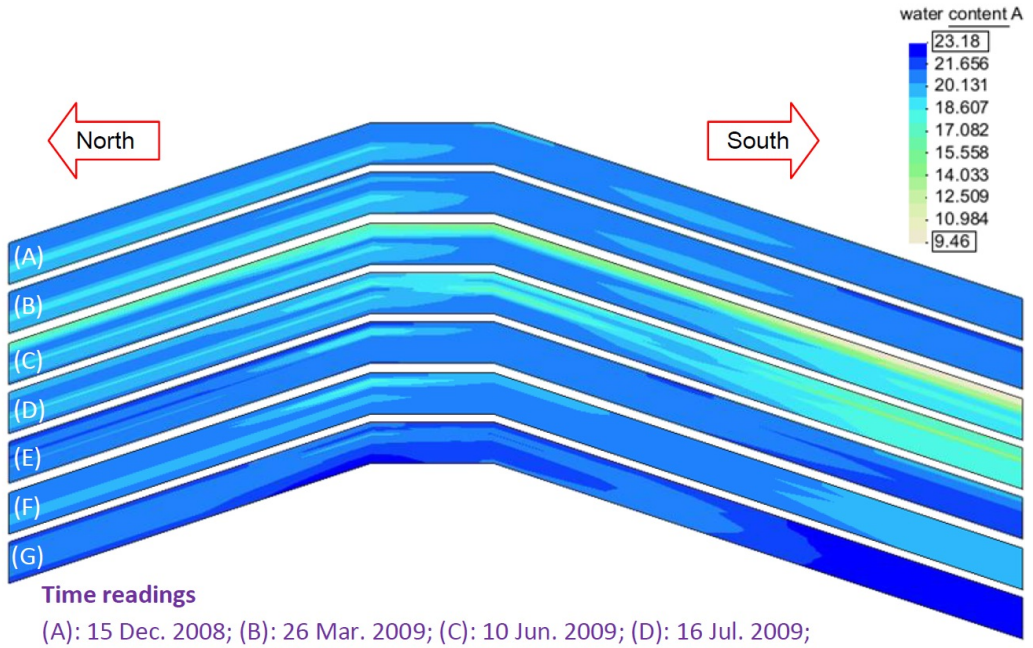

(A): 15 Dec. 2008; (B): 26 Mar. 2009; (C): 10 Jun. 2009; (D): 16 Jul. 2009;

(E): 18 Aug. 2009; (F): 08 Oct. 2009; (G): 04 Mar. 2010;

a)

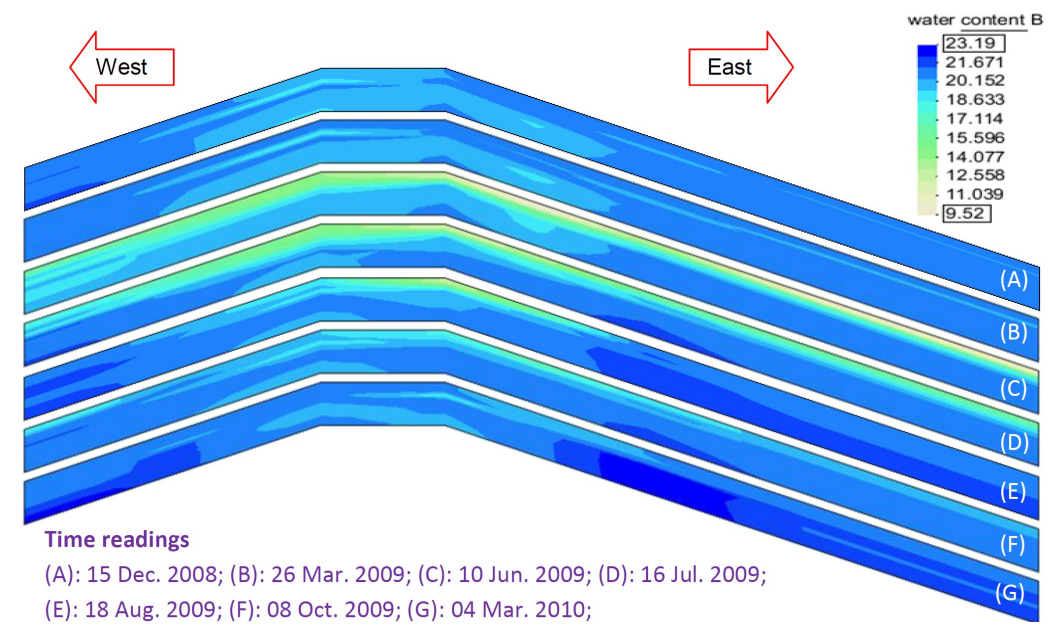


446 Figure 11. Contours of the water content at different times over a period of 1.5 years: a) in cross-section A; b)

447 in cross-section $B$.

\section{Extrapolation of the water content function for the entire structure}

In the following, $w(x, s, z, t)$ will be derived first on the basis of data gathered by the geotechnical suite only, secondly employing measurements of electrical conductivity taken by the CMD-2 probe as well.

7.1 Derivation of the water content function from the data retrieved by the geotechnical suite

In Figure 11, the water content of the two monitored cross-sections (A and B) is plotted. The water content in any other cross-section is different due to two main factors:

(i) different exposure to weather conditions (e.g. sunlight, rainfall and wind) which is a function of the local orientation of the considered cross-section with respect to North. This factor affects the ground water content along the flanks of the embankment much more than underneath the horizontal upper surface.

(ii) spatial variation of the geometrical, hydraulic and lithological properties of the cross sections along the longitudinal coordinate $s$. Heterogeneities in the compaction processes during construction, for example, are likely to cause a non-negligible spatial variation of the hydraulic conductivity along the longitudinal direction. Concerning compositional or lithological variability, this is likely to be small for the embankment examined here due to the fact that it is made of homogeneous material and its young age. However, in general, old earthen embankments are very often highly heterogeneous comprising a mixture of several materials locally available at the time of construction. 
471 Regarding factor (i), considering the axis of symmetry of the cross-section (axis $\mathrm{z}$ in Figure

472 1a), exposure to each single weather element (e.g. wind, sunrays, rainfall droplets, etc.) gives rise to a variation of water content which is either anti-symmetrical or nil in the case of equal exposure (e.g. no wind and vertical sunrays), but the combination of the single weather elements, i.e. the sum of the anti-symmetrical variations of water content due to exposure to wind, exposure to sunrays, etc., may give rise to a non-negligible symmetrical variation of water content as well. The anti-symmetrical part is a function of the orientation of the crosssection considered whereas the symmetrical one is a function of the longitudinal coordinate $s$. Regarding factor (ii), geometrical, hydraulic and lithological variations in the embankment 480 imply a variation of water content which in authors' opinion is much larger along the 481 longitudinal coordinate $s$ than within each single cross-section and therefore is mainly symmetrical. In summary, the water content variation in the embankment depends on both cross-section orientation and cross-section position. The latter is expressed by the longitudinal distance from a reference cross section (coordinate $s$ ). To better account for the variation of water content due to these geometrical factors, cross-section orientation and cross-section position, it is convenient to split the water content function, $w(x, s, z, t)$, into two parts, a symmetrical, $w^{s}$, and an anti-symmetrical one, $w^{a}$, with respect to the axis of symmetry of the cross-section:

$w^{s}(x, s, z, t)=\frac{w(x, s, z, t)+w(-x, s, z, t)}{2}$ and $w^{a}(x, s, z, t)=\frac{w(x, s, z, t)-w(-x, s, z, t)}{2}$.

To account for the influence of cross-section orientation, it is convenient to employ a

491 function $\theta(s)$, with $\theta$ being the angle between $s_{t}$, direction normal to the cross-section, and a 492 reference direction here chosen as the geographical North (see Figure 12a). Considering 493 measurements of water content at discrete time points $t_{k}, w^{a}{ }_{k}(x, s, \mathrm{z})=w^{a}\left(x, s, z, t=t_{k}\right)$ can be 
494 expressed as the weighted average of the values of water content, $495 w_{i ; k}^{a}(x, z)=w^{a}\left(x, s=s_{i}, z, t=t_{k}\right)$, recorded at $t=t_{k}$ in the $\mathrm{N}$ instrumented cross-sections:

496

$w^{a}{ }_{k}(x, s, z)=w^{a}\left(x, s, z, t=t_{k}\right)=\sum_{i=1}^{N} w_{i ; k}^{a}(x, z) \cdot \alpha_{i}(\theta)$

497 with $\alpha_{i}(\theta)$ being weight functions accounting for the anti-symmetrical water content 498 variation in the embankment. The simplest choice for $\alpha_{i}(\theta)$ is to consider a linear 499 interpolation between the values of water content measured at the $N$ instrumented sections as 500 illustrated in Figure 12c, so that:

$$
\alpha_{i}(\theta)=\left\{\begin{array}{cccc}
1 & \text { for } & \theta=\theta_{i} & \forall i \in[1, . . N] \\
0 & \text { for } & \theta=\theta_{j \neq i} & \forall i, j \in[1, . . N] \\
1-\frac{\left(\theta-\theta_{i}\right)}{\left(\theta_{i+1}-\theta_{i}\right)} & \text { for } & \theta_{i} \leq \theta \leq \theta_{i+1} & \forall i \in[1, . . N] \\
1+\frac{\left(\theta-\theta_{i}\right)}{\left(\theta_{i-1}-\theta_{i}\right)} & \text { for } \quad \theta_{i-1} \leq \theta \leq \theta_{i} & \forall i \in[1, . . N]
\end{array}\right.
$$

502 In general, it is advisable to instrument cross-sections forming equal angles between them so

503 that all the weight functions have the same periodicity in $\theta$. Two sections are suggested as the

504 minimum number required for the procedure to work.

505 Analogously, with regard to the symmetrical part of the water content variation, $506 w^{s}{ }_{k}=w^{s}\left(x, s, z, t=t_{k}\right)$ is obtained as the weighted average of the values of water content,

$507 w_{i ; k}^{s}=w^{s}\left(x, s=s_{i}, z, t=t_{k}\right)$, recorded in the $\mathrm{N}$ instrumented cross-sections at $t=t_{k}$ :

$w^{s}{ }_{k}(x, s, z)=w^{s}\left(x, s, z, t=t_{k}\right)=\sum_{i=1}^{N} w_{i ; k}^{s}(x, z) \cdot \beta_{i}(s)$

509 with $\beta_{i}(s)$ being weight functions that depend on $s$ rather than $\theta$. Considering again a linear

510 interpolation between the values of water content measured at the $N$ instrumented sections as

511 illustrated in Figure 12d, $\beta_{i}(s)$ are here defined as: 
$\beta_{i}(s)=\left\{\begin{array}{cccc}1 & \text { for } & s=s_{i} & \forall i \in[1, . . N] \\ 0 & \text { for } & s=s_{j \neq i} & \forall i, j \in[1, . . N] \\ 1-\frac{\left(s-s_{i}\right)}{\left(s_{i+1}-s_{i}\right)} & \text { for } & s_{i} \leq s \leq s_{i+1} & \forall i \in[1, . . N] \\ 1+\frac{\left(s-s_{i}\right)}{\left(s_{i-1}-s_{i}\right)} & \text { for } & s_{i-1} \leq s \leq s_{i} & \forall i \in[1, . . N]\end{array}\right.$

513 Unlike the case of the $\alpha_{i}$ functions, for $0 \leq s \leq s_{1}, \beta_{1}=1$ whilst for $s_{N} \leq s \leq L, \beta_{\mathrm{N}}=1$ with $L$

514 being the total length of the embankment. This means that for $0 \leq s \leq s_{1}$, $515 \quad w^{s}\left(x, s, z, t=t_{k}\right)=w^{s}\left(x, s=s_{1}, z, t=t_{k}\right) \quad$ whilst $\quad$ for $\quad s_{N} \leq s \leq L, \quad w^{s}\left(x, s, z, t=t_{k}\right)=$ $516=w^{s}\left(x, s=s_{N}, z, t=t_{k}\right)$. This is because in the regions $0 \leq s \leq s_{1}$ and $s_{N} \leq s \leq L$, there is only

517 water content measurements are available only for 1 section so that no interpolation can be carried out. Obviously in the choice of the location of the $1^{\text {st }}$ and $\mathrm{N}^{\text {th }}$ cross-sections, care

519 should be taken to minimise the length of the longitudinal segments $s_{1}-0$ and $L-S_{N}$.

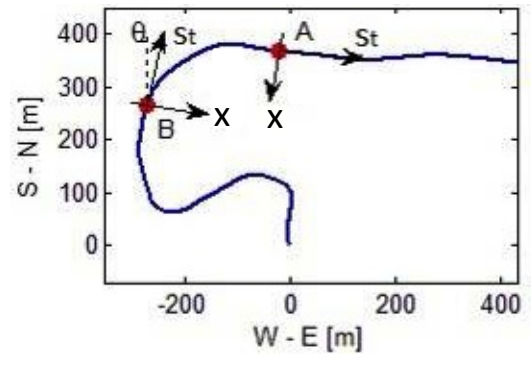

a)

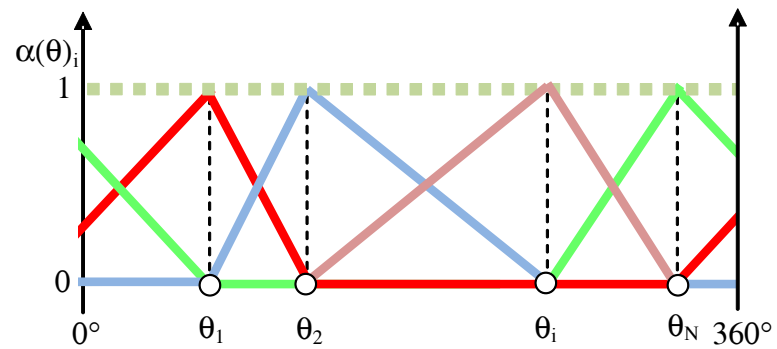

c)

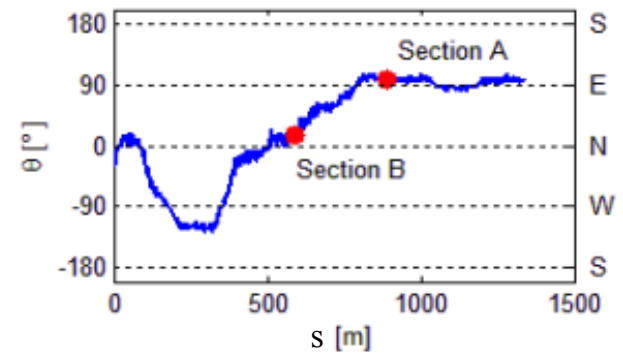

b)

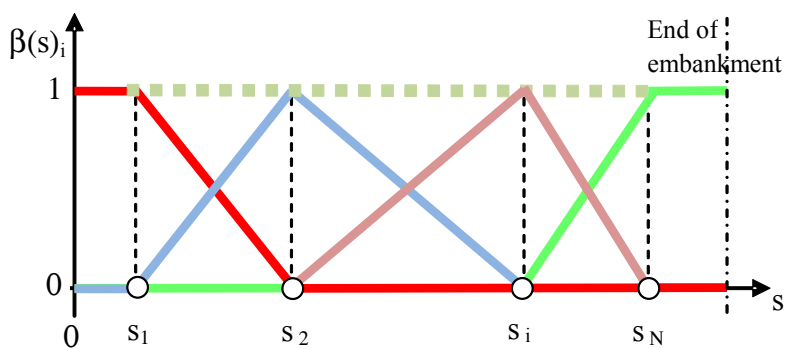

d)

Figure 12. (a) plan view of the embankment layout; (b) orientation of the longitudinal axis of the embankment with respect to the North; $c) \alpha$ weight functions against cross-section orientation; $d) \beta$ weight functions against longitudinal coordinate $s$. 
529 (3) and (5) into Eq. (1):

530

$$
w_{k}(x, s, z)=w\left(x, s, z, t=t_{k}\right)=\sum_{i=1}^{N} w_{i ; k}^{a}(x, z) \cdot \alpha_{i}(\theta)+\sum_{i=1}^{N} w_{i ; k}^{s}(x, z) \cdot \beta_{i}(s)
$$

531 In our case $N=2$, so that $w_{k}(x, s, z)$ is calculated as:

$w_{k}(x, s, z)=w\left(x, s, z, t=t_{k}\right)=w^{a}\left(x, s=s_{1}, z, t=t_{k}\right) \cdot \alpha_{1}(\theta)+w^{a}\left(x, s=s_{2}, z, t=t_{k}\right) \cdot \alpha_{2}(\theta)+$

$w^{s}\left(x, s=s_{1}, z, t=t_{k}\right) \cdot \beta_{1}(s)+w^{s}\left(x, s=s_{2}, z, t=t_{k}\right) \cdot \beta_{2}(s)$

with 1 and 2 indicating sections A and B respectively. Note that Eq. (7) provides an analytical expression for the water content in any point of the embankment at the discrete time points $t_{k}$.

So, provided that sufficiently small space intervals between instrumented cross-sections are employed and sufficiently small time intervals are used, the water content in the embankment could, in principle, be monitored as accurately as desired. So, one may be tempted to conclude that the use of the geotechnical suite alone is good enough for the health monitoring of the embankment. However, maintenance costs of the geotechnical suite over the typical lifespan of flood defence earth embankments (at least 50 years but more often 100-200 years) are higher than the costs for a monitoring programme based on geophysical measurements which only entail non-invasive periodic walk-over surveys. More importantly, only two sections have been used here. With regards to this point, in the authors' opinion, the proposed geotechnical suite may be employed as the only monitoring method, but in order to obtain accurate results, many more sections in the embankment should be monitored. If only a few sections are employed to keep the monitoring costs within affordable limits, geophysical probes are necessary to integrate the discrete geotechnical data with spatially continuous measurements acquired along the entire embankment. Such a procedure is detailed below. 


\subsection{Integration of the geophysical data with the geotechnical suite}

552 Herein the variable $\sigma$ will be employed to represent the ground electrical conductivity which

553 is a function of both space and time, hence $\sigma=\sigma(x, s, z, t)$. However, electromagnetic

554 probes provide a measure of $\sigma$ which is averaged over a prismatic volume of ground where 555 the induced electrical field is non-zero. Considering a generic cross-section of the 556 embankment, we define:

$$
\bar{\sigma}(s, t)=\frac{\int_{A_{C M D}} w(x, s, z, t) d x d z}{A_{C M D}}
$$

with $A_{C M D}=b \cdot d, b$ being the distance between the two ends of the electromagnetic probe (hence corresponding to the width of the portion of the embankment cross-section where the induced electrical field is non-zero) and $d$ the so-called effective depth, i.e. the depth of the induced electromagnetic field. Note that $A_{C M D}$ is independent of the cross-section considered, i.e. its size does not vary with $s$, but depends on the type of electromagnetic probe employed

563 (for this reason we called it $A_{C M D}$ ). The effective depth is a function of the type of ground and 564 of the vertical distance from the portable device to ground level. $d$ is an unknown that we determined by trial and error selecting the value which provides the best correlation between electrical conductivity and water content as illustrated later on (see Figure 14).

In Figure 13a, the measurements taken by the CMD-2 device at six time points along the entire embankment, $\bar{\sigma}_{k}(s)=\bar{\sigma}\left(s, t=t_{k}\right)$, are shown. It emerges that the shape of the curves is approximately the same for all the times considered. Now let us introduce the spatial average of $\bar{\sigma}(s, t)$ over the entire embankment length as:

$571 \quad \overline{\bar{\sigma}}(t)=\frac{\int_{s=0}^{s=L} \bar{\sigma}(s, t) d s}{L}$ 
with the second above score bar denoting the spatial average over the longitudinal coordinate 573

$s$. Then, we can introduce the normalised cross-sectional average electrical conductivity as:

$574 \quad \bar{\sigma}_{0}(s, t)=\frac{\bar{\sigma}(s, t)}{\overline{\bar{\sigma}}(t)}$

575 The normalised measurements taken at times $t_{k}$, i.e. $\bar{\sigma}_{0_{k}}=\bar{\sigma}_{0}\left(s, t=t_{k}\right)$, are plotted in Figure

576 13b. From the figure, it emerges that the curves coincide almost perfectly. This leads to

577 consider the average of $\bar{\sigma}_{0_{k}}=\bar{\sigma}_{0}\left(s, t=t_{k}\right)$ over time:

$578 \bar{\sigma}_{0}(s)=\underset{k}{\operatorname{average}} \bar{\sigma}_{0}\left(s, t=t_{k}\right)=\underset{k}{\operatorname{average}}\left(\frac{\bar{\sigma}\left(s, t=t_{k}\right)}{\overline{\bar{\sigma}}\left(t=t_{k}\right)}\right)$

579 as the representative curve of the conductivity of the embankment. Note that herein the

580 underscore bar denotes time average. The measurements were taken by an operator walking

581 above the centre of the embankment horizontal upper surface. Therefore, they cannot detect

582 any conductivity variation due to different cross-section orientations, i.e. they are

583 independent of the angle $\theta$. The time-independent function $\overline{\boldsymbol{\sigma}}_{0}(s)$ can be thought of as a

584 unique identifier of the embankment expressing the variation of conductivity along the $s$

585 coordinate due to the variation of geometrical, hydraulic and lithological properties of cross-

586 sections and to the effects of exposure to weather conditions independent of cross-section

587 orientation, i.e. cross-sectionally symmetric. On the other hand, the function $\overline{\bar{\sigma}}(t)$ reflects the

588 temporal effect of climatic variations (e.g. rainfall, wind, temperature variations, etc.) and

589 aging on the ground conductivity.

590
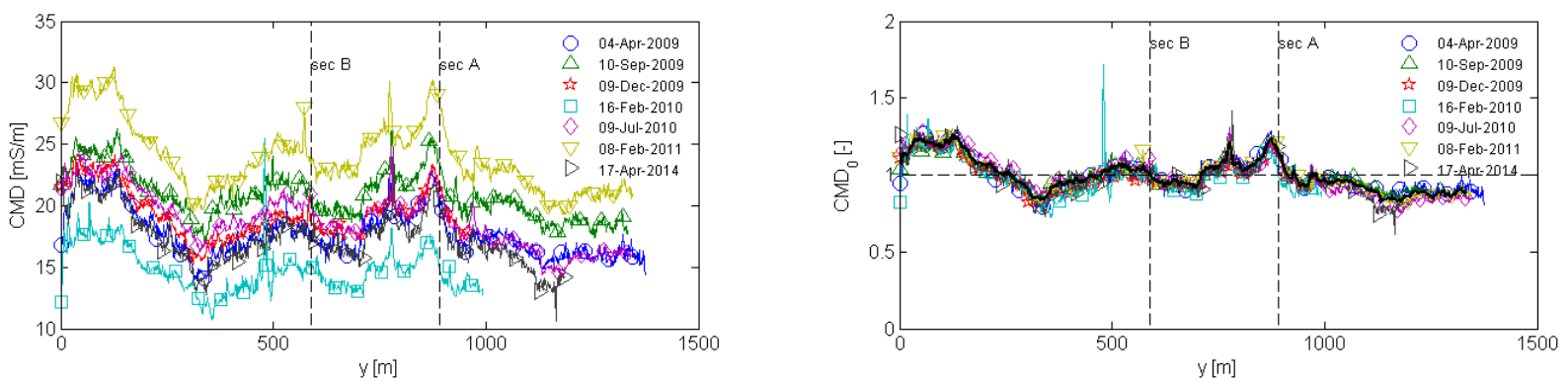
592 Figure 13. (a) electrical conductivity measurements along the embankments at seven different times; (b) 593 normalised values of conductivity measurements.

597 function $\overline{\bar{\sigma}}(t)$ :

$$
\bar{\sigma}(s, t)=\underline{\bar{\sigma}}_{0}(s) \cdot \overline{\bar{\sigma}}(t)
$$

599 In the following it will be shown that this split is a necessary step to find a correlation

600 between water content and electrical conductivity. First, let us define the average water

601 content in the portion of the embankment cross-sections where the electromagnetic field is

602 non-zero, i.e. $A_{C M D}$ :

$603 \bar{w}(s, t)=\frac{\int_{A_{C M D}} w(x, s, z, t) d x d z}{A_{C M D}}$

604 Analogously to $\bar{\sigma}(s, t)$, we can split $\bar{w}(s, t)$ into two functions: a time independent 605 dimensionless function, $\underline{\bar{w}}_{0}(s)$, which accounts for the effect of cross-section orientation and 606 position on the ground water content and the space independent dimensional function, $\overline{\bar{w}}(t)$, 607 which accounts for the effect of climatic variations and aging on the ground water content:

$608 \bar{w}(s, t)=\underline{\bar{w}}_{0}(s) \cdot \overline{\bar{w}}(t)$

$609 \overline{\bar{w}}(t)$ represents the spatial average of the water content on the cross-sectional area $A_{C M D}$ and 610 along the longitudinal coordinate $s$ :

$611 \overline{\bar{w}}(t)=\frac{\int_{0}^{L} \frac{\int_{A_{C M D}}\left[\sum_{i=1}^{N} w^{a}\left(x, s=s_{i}, z, t\right) \cdot \alpha_{i}(\theta)+\sum_{i=1}^{N} w^{s}\left(x, s=s_{i}, z, t\right) \cdot \beta_{i}(s)\right] d x d z}{A_{C M D}} d s}{L}$ 
612 To look for a correlation between the measured electrical conductivity and water content,

613 we shall consider the time dependent functions $\overline{\bar{w}}(t)$ and $\overline{\bar{\sigma}}(t)$. Before doing so, we need to

614 account for the strong dependency exhibited by the ground electrical conductivity on

615 temperature (Keller and Frischknecht, 1966). Recently Hayley et al., (2007) investigated this

616 dependency for a range of temperatures corresponding to our case (temperature varying

617 between 0 and 25 Celsius) on a glacial till finding a linear dependency of the type:

$618 \sigma=\sigma_{25}[C(T-25)+1]$

619 with $\sigma$ being the electrical conductivity measured at the temperature $T$ and the constant $620 C=0.02$. To account for the effect of temperature on the measured electrical conductivity, we 621 expressed all the measured values relative to the same reference temperature before 622 correlating them to the water content. As shown in (Hayley et al., 2007), manipulating Eq. 623 (16), the following expression for the calculation of $\sigma$ relative to the chosen reference 624 temperature is obtained:

625

$\sigma_{r e f}=\sigma \frac{1+C\left(T_{r e f}-25\right)}{1+C(T-25)}$

626 with $\sigma_{r e f}$ being the value of electrical conductivity relative to the reference temperature $T_{r e f}$.

627 Here, we chose $T_{r e f}=15$ Celsius to minimise the amount of temperature compensation.

628 Employing Eq. (17), we calculated $\sigma_{r e f}$ from the in-situ values of $\sigma$ and $T$.

629 In Figure 14, the water content measured at the time points $t_{k}, \overline{\bar{w}}\left(t=t_{k}\right)$ is plotted against 630 the electrical conductivity measured at the same time points, $\overline{\bar{\sigma}}_{r e f}\left(t=t_{k}\right)$. It emerges that the 631 relationship between $\overline{\bar{w}}(t)$ and $\overline{\bar{\sigma}}_{r e f}(t)$ is well captured by a linear function so that:

$632 \quad \overline{\bar{w}}(t)=m \overline{\bar{\sigma}}_{r e f}(t)+q$ 
633 with $m$ and $q$ determined by best fit (see Figure 14). Substituting Eq. (17) into Eq. (18), it 634 becomes:

$635 \quad \overline{\bar{w}}(t)=m \overline{\bar{\sigma}}(t) \frac{1+C\left(T_{r e f}-25\right)}{1+C(T-25)}+q$

636 Eq. (19) links the in-situ measured water content to the in-situ measured electrical 637 conductivity.

638

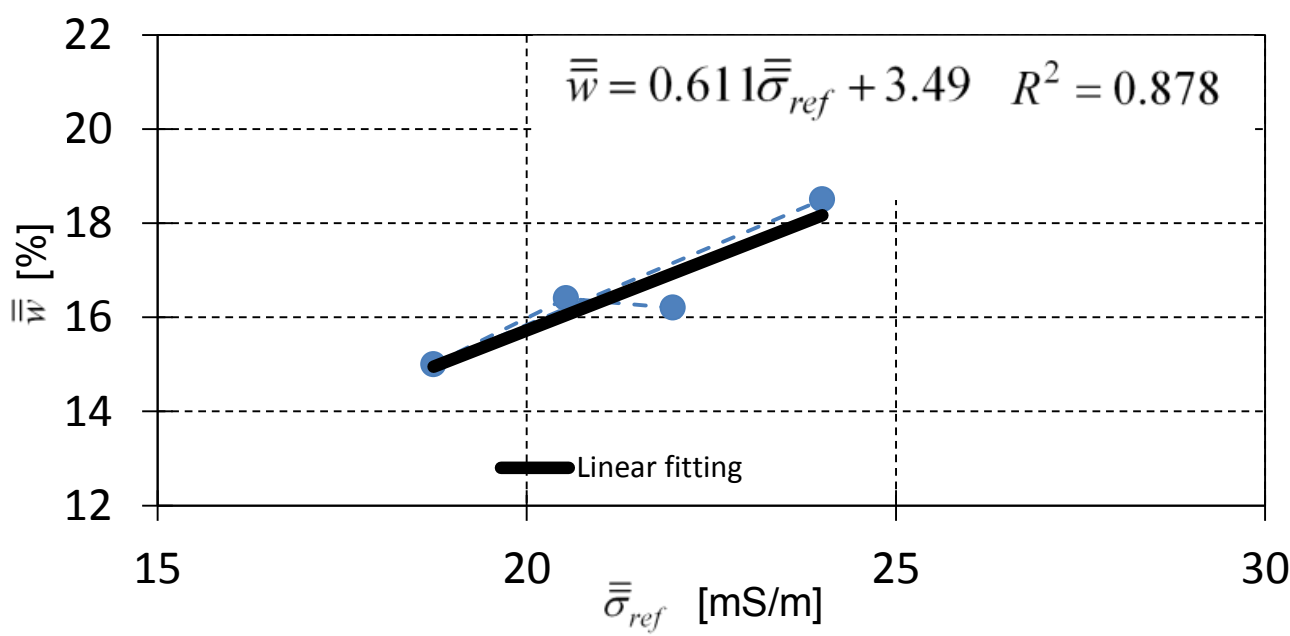

639 Figure 14. Correlation obtained over the monitored 2 year time period between $\overline{\bar{\sigma}}_{\text {ref }}$, electrical conductivity at 640 the chosen reference temperature $\left(T_{\text {ref }}=15^{\circ} \mathrm{C}\right)$, and $\overline{\bar{w}}$ calculated for an effective depth of $d=0.2 \mathrm{~m}$.

641

642 In order to work out the water content in any point of the embankment, $w(x, s, z, t)$, the 643 space independent dimensional function $\overline{\bar{w}}(t)$, must be multiplied by a normalised time 644 independent function, $\underline{w}_{0}(x, s, z)$, so that:

$645 w(x, s, z, t)=\underline{w}_{0}(x, s, z) \cdot \overline{\bar{w}}(t)$

646 Following the approach adopted in par. 7.1, $w_{0}(x, s, z)$ is split into the summation of two 647 parts, an anti-symmetrical and a symmetrical one:

648 $\underline{w}_{0}(x, s, z)=\underline{w}_{0}{ }^{a}(x, s, z)+\underline{w}_{0}{ }^{s}(x, s, z)$ 
649 As in par. 7.1, we assume $\underline{w}_{0}{ }^{a}(x, s, z)$ to be the time average of the linear combination of the

650 functions expressing the normalised water content measured at times $t_{k}$ at the $\mathrm{N}$ instrumented

651 cross-sections, $w_{0_{i ; k}}^{a}(x, z)$ :

652

$\underline{w}_{0}^{a}(x, s, z)=\underset{k}{\operatorname{average}}\left[\sum_{i=1}^{N} w_{0_{i, k}}^{a}(x, z) \cdot \alpha_{i}(\theta)\right]$

653 According to standard normalisation procedures, $w_{0_{i ; k}}^{a}(x, z)$ and $w_{0_{i ; k}}^{s}(x, z)$ are defined as:

654

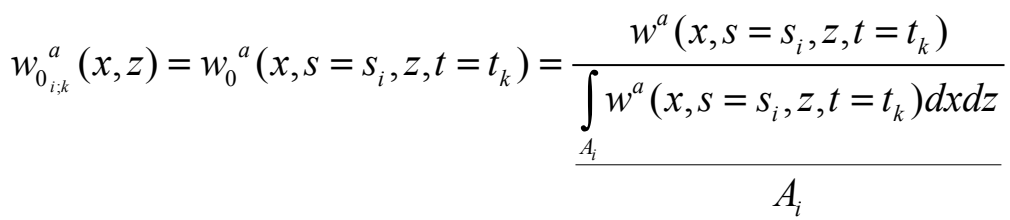

655

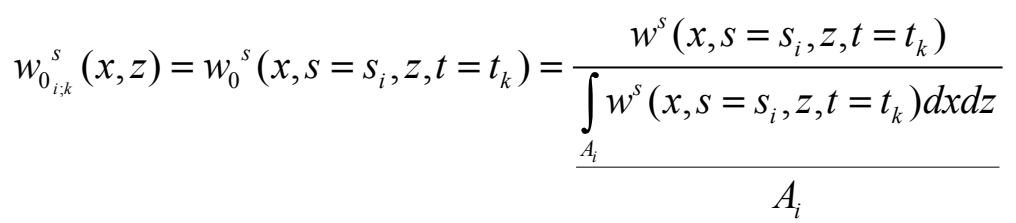

656

657

658

659

660

661

662

663

664

665

666

with $A_{i}$ being the area of the $i^{\text {th }}$ cross section.

For the symmetrical function $\underline{w}_{0}^{s}(x, s, z)$, we assume the following expression:

$$
\underline{w}_{0}^{s}(x, s, z)=\bar{w}^{s}(s, t) \cdot \underline{\bar{\sigma}}_{0}(s)=\underset{k}{\operatorname{average}}\left[\sum_{i=1}^{N} w_{0_{i, k}}^{s}(x, z) \cdot \beta_{i}(s)\right] \overline{\underline{\sigma}}_{0}(s)
$$

The dimensionless function $\overline{\bar{\sigma}}_{0}(s)$ accounts for the spatial variation of water content along the longitudinal direction of the embankment detected by the geophysical probe during walkover surveys. Eq. (24) constitutes an important improvement in comparison with Eq. (4) since the time average of the linear combination of the water content values measured at the $\mathrm{N}$ instrumented cross sections, average $\left[\sum_{i=1}^{N} w_{0_{i ; k}}^{s}(x, z) \cdot \beta_{i}(s)\right]$, is adjusted by multiplication with $\underline{\bar{\sigma}}_{0}(s)$ to account for the spatial variation of conductivity detected by the geophysical survey along the longitudinal direction. The advantage of employing geophysics is now apparent since it provides measurements which are continuous along the spatial coordinate $s$. This 
667 allows improving the quality of the estimated water content especially in the zones of the embankment farthest away from the geotechnically instrumented cross-sections.

669 So far the symmetrical component of the water content, $\underline{w}_{0}{ }^{s}(x, s, z)$ has been related to 670 the geophysical measurements of the variation of ground electrical conductivity along the $s$ 671 coordinate, i.e. dependent on cross-section position. In principle it should also be possible to 672 relate the anti-symmetrical component of the water content $\underline{w}_{0}{ }^{a}(x, s, z)$ to geophysical 673 measurements of the variation of ground electrical conductivity due to cross-section 674 orientation, i.e. dependent on the angle $\theta$. Let us recall that the geophysical measurements 675 were taken by an operator walking above the centre of the embankment horizontal upper 676 surface where the effect of cross-section orientation is negligible so that the measurements 677 are a function of cross-section position only (hence of the $s$ coordinate only). To correlate 678 electrical conductivity to the anti-symmetrical part of the water content, measurements of 679 electrical conductivity along more than one path would be needed with some of them being 680 along the embankment flanks. However, these measurements would be likely affected by a 681 large error since it is very difficult to walk for long distances on the embankment flanks 682 (which are variously inclined), keeping a constant geometrical height (z coordinate).

683 Now, substituting Eq. (19), (22) and (24) into Eq. (20), the water content at the time $t_{l}$ of 684 the geophysical measurement $w\left(x, s, z, t=t_{l}\right)$, can be derived as a function of the average 685 cross-sectional ground conductivity, $\bar{\sigma}\left(s, t=t_{l}\right)$ :

686

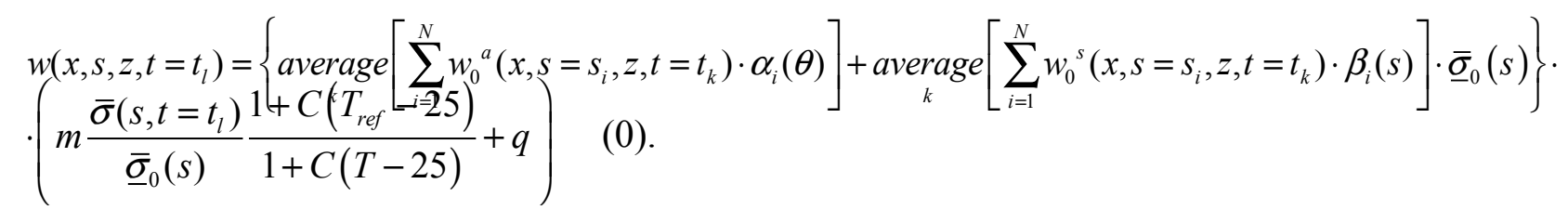


Eq. (25) provides the analytical expression to be employed to monitor the water content in the embankment carrying out periodic walk-over surveys over a time period which can be much longer than the time of activity of the geotechnical suite (i.e. $\left.t_{l} ? t_{k}\right)$.

692 sections $(s=2,182,672$ and $972 \mathrm{~m})$ from the electrical conductivity profile of the

693 embankment, measured during a walk-over survey carried out on $17^{\text {th }}$ April 2014 (so for

$694 t_{l}>t_{k}$ ), are plotted in Figure 15. In order to provide a validation of the proposed method, a

695 few soil samples were retrieved from the embankment and brought to the laboratory for 696 accurate measurement. In the plots of Figure $15 c$ and $d$, the experimental values of water 697 content are reported as triangles. Comparing the predictions of the method with the 698 experimental measurements of water content, the predictions show to be in very good 699 agreement with the experimentally measured values. This is quite remarkable especially in 700 light of the fact that the measurements were taken at a time (1 $7^{\text {th }}$ April 2014) well beyond the 7012 year period within which the geotechnical and geophysical measurements had been 702 performed to calibrate the model.
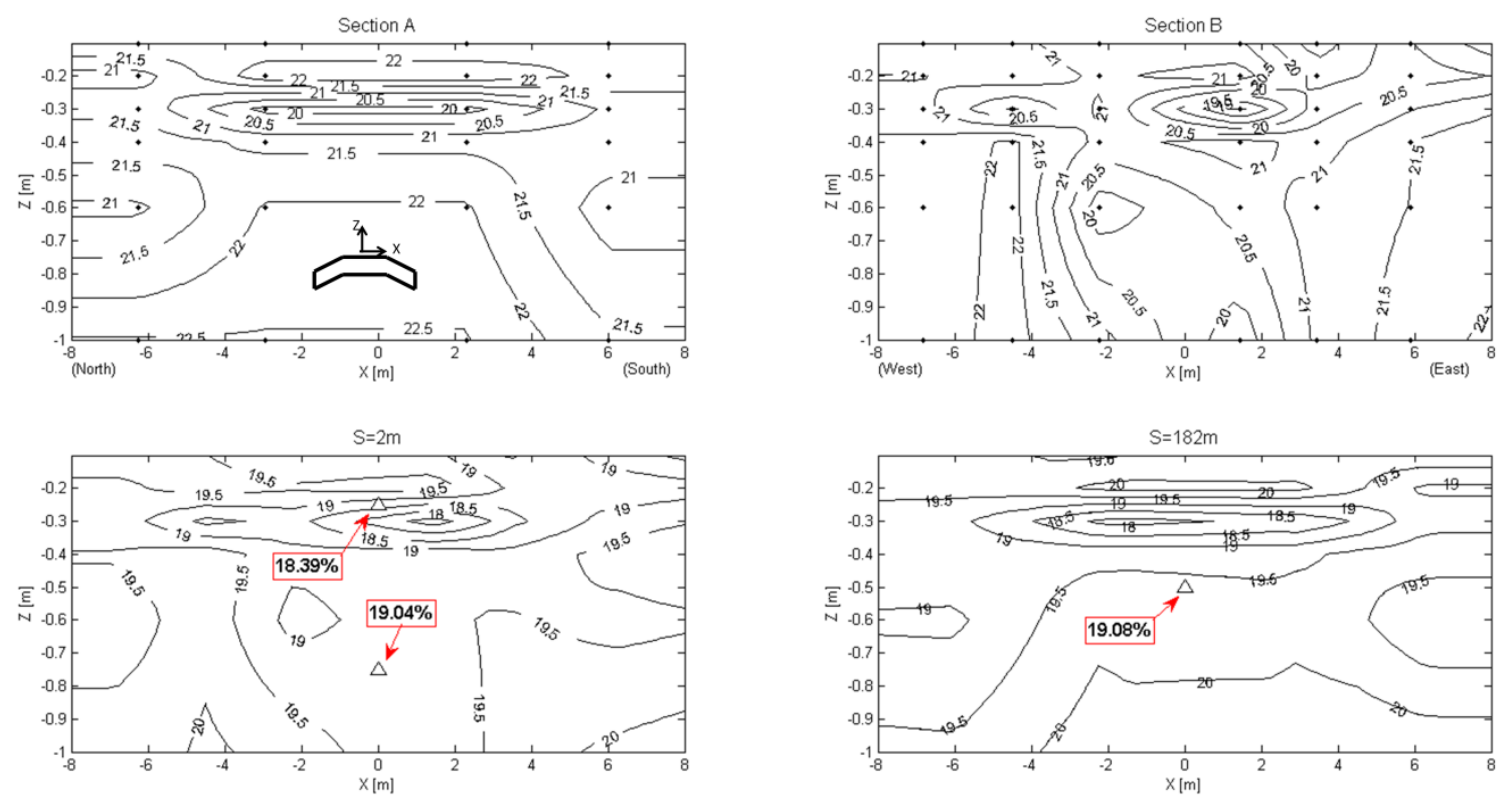

option. samples.

Figure 15. values of the water content estimated from the electrical conductivity measured by the CMD-2 during a walk over survey carried out on $17^{\text {th }}$ April 2014 employing the proposed methodology . a) water content in section $A ; b)$ water content in section $B ; c)$ water content at $s=2 m$; d) water content at $s=182$. The triangles in figures $c$ ) and $d$ ) indicate the value of water content measured in the laboratory from the retrieved in-situ

\subsection{Options for long term monitoring}

In light of our results, three options of increasing accuracy but also requiring increasing costs emerge for the monitoring of the embankment water content over time. The first and cheapest option consists of using meteorological data only; the second more expensive option relies on periodic walk-over surveys to retrieve geophysical data employing electromagnetic probes; the third most expensive option requires both periodic walk-over surveys to retrieve geophysical data and measurements in a number of cross-sections from a permanent geotechnical suite. The first option requires the use of the geotechnical suite for an initial limited period of time without any periodic (geotechnical or geophysical) measurement at subsequent times. In the second option, the integration of geotechnical data with geophysical ones (section 7.2) is carried out in a first limited initial period only whereas in the third option it is carried out repeatedly during the whole lifetime of the structure. The second option provides predictions more robust than the first one since the first option relies on a relationship between meteorological data and variation of the water content established over the initial time of monitoring which is expected to change over time with the ageing of the structure. Depending on the importance of the structure and the available financial resources, the authorities in charge of the maintenance of the embankments can select the most suitable 


\section{A proposal for a susceptibility index to desiccation fissuring}

730 Here, a proposal for a susceptibility index for a failure mechanism that can be directly related 731 to the presence of desiccation cracks is put forward. Cooling and Marsland, (1953), Marsland and Cooling, (1958) and more recently Morris et al., (2007) and Dyer et al., (2009) have described failure mechanisms which take place when water overflows the embankment crest in the presence of an interconnected pattern of vertical and horizontal cracks underneath the horizontal upper surface and the landward flank of the embankment. Overtopping water seeping downwards into the open cracks leads to the progressive uplift and removal of intact blocks of ground, first from the landward flank and subsequently from the horizontal upper surface. This failure mechanism is particularly dangerous since it leads to the development of a fast breach which can lead to quick flooding. The formation of extensive cracks is also detrimental for the structure since it favours internal piping.

Tests run by Tang et al., (2012) on clay samples of various shape show that after 4 wetting-drying cycles, the onset of cracks can be uniquely related to the value of the soil water content, i.e. it becomes independent of the wetting-drying history. In Costa et al. (2013), it is shown that once the water content in clayey soils lowers below a threshold value near the plastic limit, $w_{\text {plastic }}$, no additional cracks are formed. The determination of a threshold value of water content at which an interconnected network of cracks is formed and equally the determination of a critical threshold value for piping failure are challenging issues outside of the scope of this paper. Unsaturated soil mechanics and the formation of desiccation fissures in cohesive soils are topics of intense current research. Therefore, it is 750 plausible to expect that in the future, with further results becoming available, it will be 751 possible to establish a better susceptibility index based on less crude assumptions. The index here proposed has been conceived to provide a purely qualitative indication about which zones of the embankment are liable to fissuring; so it has not to be relied upon for 
quantitative predictions on the level of hazard, or on the likelihood of failure in these zones. Here, for sake of simplicity, we assumed this threshold to coincide with the plastic limit $\left(w_{\text {plastic }}\right)$ of the till. As a first approximation, we also assumed that the ground zones where the water content is below the plastic limit are fissured so that the portion of cross section where $w<w_{\text {plastic }}$ is considered fully fissured; whereas the portion where $w>w_{\text {plastic }}$ is considered intact. The sought susceptibility index has to reflect how far a cross-section is from the critical condition leading to failure. Hence, the index here proposed is defined as the ratio of the sectional area where cracks have formed, $A_{f i s}$, over the sectional area required for the development of the considered failure mechanism, $A_{\Omega}$ :

$763 I=\frac{A_{\text {fis }}}{A_{\Omega}}$ with $0<\mathrm{I}<1$

764 The size of $A_{\Omega}$ is a property of the ground. In Dyer et al. (2009), a maximum characteristic depth for the formation of an interconnected network of cracks $0.6 \mathrm{~m}$ deep was observed in trial pits excavated in embankments made of glacial tills similar to the embankment investigated in our paper. Therefore, a depth of $0.6 \mathrm{~m}$ was used to determine the sectional domain employed for the calculation of $A_{\Omega}$ (see Figure 16a).

In Figure 16b, the function $\mathrm{I}(\mathrm{s})$ representing the value of the index along the embankment, has been plotted for two different time points. It can be observed that in winter the susceptibility index is nil (i.e. no fissuring is expected) in most of the embankment, apart from two rather small zones where the index spikes up to 1 . Conversely in summer, the index assumes values larger than 0 in the whole embankment. Figure $16 \mathrm{~b}$ is sufficient to identify the zones of the embankment which are most in need of remedial measures. However, it may be useful to define categories of risk for intervention protocols whereby the type of intervention and its urgency are related to the established categories. Here, as an example, three categories were established: no risk (green color) associated to $0<\mathrm{I}<0.5$, moderate risk 
778 (yellow color) associated to $0.5<\mathrm{I}<0.90$, and high risk (red color) associated to $0.90<\mathrm{I}<1$. In 779 the zones classed as high risk ( $>0.9$ ), cracks were observed during both the winter and the

780 summer period (see Figure 16e). Also, the plots in Figure $16 c$ and $d$ provide a user-friendly 781 visualisation of the location of the most critical zones in the embankment.

782

783

784

785

786

787

788

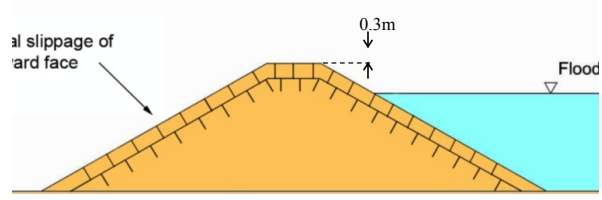

a)

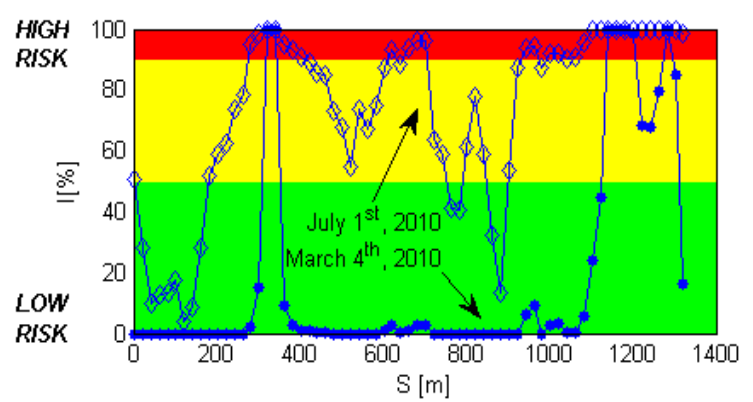

b)

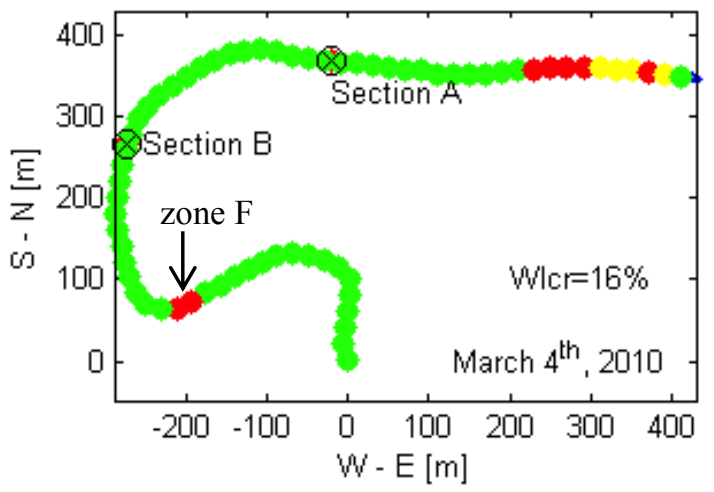

c)

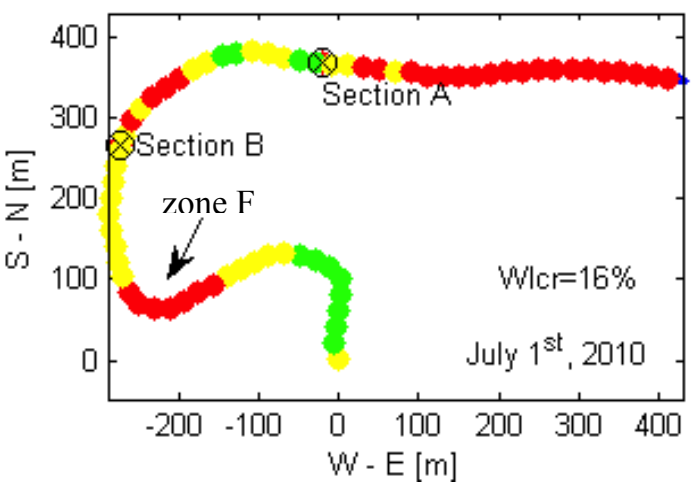

d) 


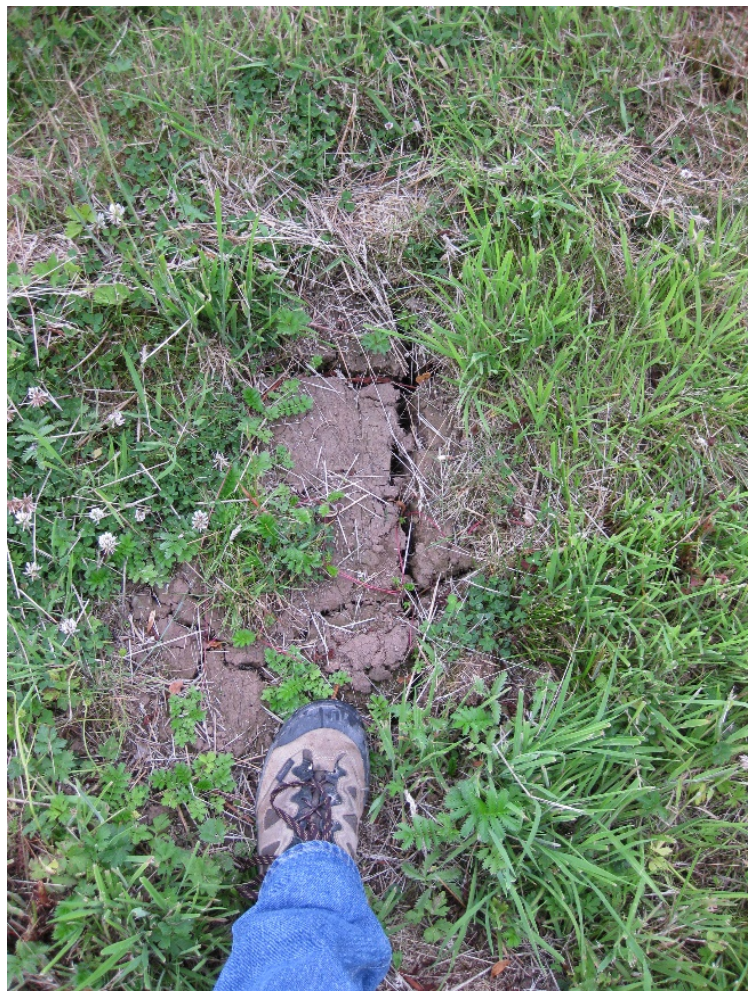

Figure 16. (a) representation of the total area $A_{\Omega}$ considered in the calculation of the susceptibility index (figure modified from Dyer et al., 2009); (b) comparison between the calculated susceptibility index along the embankment on March $4^{\text {th }}$ and July $1^{\text {st }}, 2010 ;(c)$ and (d) risk map of the embankment drawn on March $4^{\text {th }}$ and on July $1^{\text {st }}$, 2010; (e) picture of a surficial crack system taken in zone F of Figures $c$ and $d$.

\section{Conclusions}

797 In this paper, a cost effective methodology for the quantitative assessment of the potential for

798 desiccation fissuring for earthen embankments and tailing dams was established. Currently,

799 monitoring and condition assessment of embankments is performed by visual inspections at

800 set intervals. The proposed methodology is simple and suitable to be employed over the

801 entire lifetime of the structures by the authorities in charge of their maintenance. This

802 methodology paves the way for a radical improvement from the methods currently employed

803 moving to a quantitative assessment of the liability of long embankments (levees) to

804 desiccation fissuring. 
The methodology is based on the use of a suite of standard geotechnical probes for the measurement of the water content in a limited number of locations in the embankment

807 integrated with periodic non-invasive geophysical measurements from walkover surveys 808 employing portable electromagnetic probes. Most of the data from the geotechnical suite 809 were acquired by automatic reading systems involving minimal manpower. An innovative 810 calibration procedure was employed to calibrate the geotechnical probes (theta probe, profile 811 probe, diviner, etc.) in-situ by cross-comparison.

812 An index of susceptibility to desiccation induced deterioration was defined. Contour plots 813 of the calculated index provide an easy-to-be-used visual tool to monitor the health state of 814 the structure and identify the most critical zones to prioritise remedial interventions. Also a

815 protocol to monitor the susceptibility of earthen embankments to desiccation induced 816 deterioration over their lifespan is proposed based on three hierarchical levels of increasing 817 cost but also of increasing accuracy. The first and cheapest option consists of using 818 meteorological data only; the second more expensive option relies on periodic walk-over 819 surveys to retrieve geophysical data from the site; whereas the third most expensive option 820 requires both measurements in a number of cross-sections from a permanent geotechnical suite and periodic walk-over surveys to retrieve geophysical data.

\section{Acknowledgements}

824 This research was carried out within the project "Long term deterioration of flood 825 embankments" funded by the Scottish Executive and by grant 0708 from the ICE Research and Development Enabling Fund. Mr Marco Secondi is thanked for his help in setting out the instrumentation and acquiring and managing the database from the field. Ms Chiara Grisanti is thanked for contributing to obtain figures 9, 10 and 15 from her Bachelor thesis. 
$831 \quad i$

$832 k$

$833 m$

$834 q$

$835 x$

836 s

$837 \quad \mathrm{~s}_{\mathrm{t}}$

$838 \quad \mathrm{z}$

$839 \mathrm{P}$

$840 \quad \mathrm{X}$

$841 \quad \mathrm{Y}$

$842 \quad \mathrm{Z}$

$843 w(x, s, z, t)$

$844 w_{\text {plastic }}$

$845 \quad w^{s}(x, s, z, t)$

integer indicating the number of the embankment cross section considered integer indicating the chronological sequence of the measurement performed slope coefficient for linear interpolation in Figure 14

intercept coefficient for linear interpolation in Figure 14

local Cartesian horizontal coordinate in the embankment cross-section

global curvilinear coordinate along the longitudinal axis of the embankment

local Cartesian coordinate orthogonal to $\mathrm{x}$ and $\mathrm{z}$

local vertical downward Cartesian coordinate

vertical line (point on the embankment surface) in the cross section B of the embankment

global Cartesian coordinate

global Cartesian coordinate

global Cartesian coordinate

water content

water content at the plastic limit

symmetrical part of the cross-sectional water content

$846 \quad w^{a}(x, s, z, t) \quad$ anti-symmetrical part of the cross-sectional water content

847 $w_{k}=w\left(x, s, z, t=t_{k}\right) \quad$ water content measured at the time $t_{k}$

848 $w_{i ; k}=w\left(x, s=s_{i}, z, t=t_{k}\right) \quad$ water content measured in cross-section $i$ at time $t_{k}$ $w_{P}=w\left(x=x_{P}, s=s_{P}, z, t\right)$ water content measured along the vertical line $\mathrm{P}$ $\bar{w}(s, t)$ cross-sectional water content average. The water content is averaged over the portion of embankment 851 cross-section where the induced electric field is non zero $\left(\mathrm{A}_{\mathrm{CMD}}\right)$ 

averaged over the portion of embankment cross-section where the induced electric field is non zero ( $\mathrm{A}_{\mathrm{CMD}}$ )

$854 \bar{w}_{0}(s, t)$ normalised cross-sectional average water content

$855 \underline{w}_{0}(s)$ time average of the normalised cross-sectional average water content

$856 \alpha$ weight function

$857 \quad \beta \quad$ weight function

$858 \quad \theta \quad$ angle of $\mathrm{s}_{\mathrm{t}}$ with the $\mathrm{X}$ axis. It indicates the orientation of a cross-section with regard to the global $859 \quad$ Cartesian coordinate system

$860 \quad \sigma \quad$ electrical conductivity

$861 \bar{\sigma}(s, t)$ cross-sectional average electrical conductivity. The electrical conductivity is averaged over the portion 862 of embankment cross-section where the induced electric field is non zero $\left(\mathrm{A}_{\mathrm{CMD}}\right)$

$863 \bar{\sigma}_{k}(s)=\bar{\sigma}\left(s, t=t_{k}\right) \quad$ cross-sectional electrical conductivity average measured at the time $t_{k}$

$864 \overline{\bar{\sigma}}(t)$ space average of the electrical conductivity (average over the entire embankment). The electrical 865 conductivity is averaged over the portion of embankment cross-section where the induced electric field is non 866 zero $\left(\mathrm{A}_{\mathrm{CMD}}\right)$

$867 \bar{\sigma}_{0}(s, t)$ normalised cross-sectional average electrical conductivity.

$868 \bar{\sigma}_{0}(s)$ time average of the normalised cross-sectional average electrical conductivity

$869 \mathrm{~A}_{\mathrm{CMD}}$ portion of cross-sectional area where the induced electric field is non-zero.

$870 \mathrm{~A}_{\Omega} \quad$ portion of cross-sectional area with interconnected cracks causing a decrease of bearing capacity

$871 \mathrm{~A}_{\text {fis }} \quad$ portion of the cross-sectional area where $w<w_{\text {plastic }}$

$872 \quad \mathrm{~A}_{\mathrm{i}} \quad$ area of cross-section $i$

873 C constant

874 I $\quad$ susceptibility index 


\section{References}

877 1. Allsop W., Kortenhaus A., Morris M., Buijs F., Hassan R., Young M., Doorn N., der Meer 878 J., Van Gelder P., Dyer M., Redaelli M., Utili S., Visser P., Bettess R., Lesniewska D., 879 Horst W. (2007). Failure mechanisms for flood defence structures. EU FP7 FLOODSite $880 \quad$ task 4, Research Report: T04-06-01.

881 2. Andersen G.R., Chouinard L.E., Bouvier C., Back W.E. (1999). Ranking procedure on 882 maintenance tasks for monitoring of embankment dams. Journal of Geotechnical and Geoenvironmental Engineering, 125, 247-259.

3. Aubeny C.P., Lytton R.L. (2004). Shallow slides in compacted high plasticity clay slopes. J Geotech \& Geoenv Engrg ASCE, 130, 717-727.

4. Charles J.A. (2008). The engineering behaviour of fill materials: the use, misuse and disuse of case histories. Geotechnique, 58, 541-570.

5. Cooling L.F., Marsland A. (1953). Soil mechanics studies of failures in the sea defence banks of Essex and Kent. Proceedings of the ICE Conference on the North Sea Floods of 31 January/1 February 1953, ICE, London, 58-73.

6. Costa S., Kodikara J., Shannon B. (2013). Salient factors controlling desiccation cracking of clay in laboratory experiments. Geotechnique, 63: 18-29.

7. D'Elisio C. (2007). Breaching of sea dikes initiated by wave overtopping: A tiered and modular modeling approach. Ph.D. thesis, Univ. of Braunschweig, Germany, and Univ. of Florence, Italy.

8. De Vita P., Di Maio R., Piegari E. (2012). A study of the correlation between electrical resistivity and matric suction for unsaturated ash-fall pyroclastic soils in the Campania region (southern Italy). Environmental Earth Science, DOI 10.1007/s12665-012-1531-4. 
899 9. Di Maio R., Piegari E. (2011). Water storage mapping of pyroclastic covers through 900 electrical resistivity measurements. Journal of Applied Geophysics 75, 196-202.

901 10. Dyer M., Utili S., Zielinski M. (2009). Field survey of desiccation fissuring of flood 902 embankments. Proc. ICE Water Management 162, 221-232.

903 11. Environment Agency (2006). Condition assessment manual. Report DR 166_03_SD01

904 12. Gf Instruments (2011). Short guide for electromagnetic conductivity survey. $905 \quad$ (www.gfinstruments.cz).

906 13. GID (2014). GID reference manual. Available at www.gidhome.com/support/manuals.

907 14. Hayley K., Bentley L.R., Gharibi M., Nightingale M. (2007). Low temperature 908 dependence of electrical resistivity: implications for near surface geophysical monitoring. 909 Geophysical Research Letters, 34: L18402.

910 15. Keller G.V., Frischknecht F.C., (1966). Electrical Methods in Geophysical Prospecting. 911 Pergamon Press, Oxford, 517p.

912 16. Konrad JM., Ayad R. (1997). Desiccation of a sensitive clay: field observations. Canadian 913 Geotechnical Journal, 34: 929-942.

914 17. Marsland A., Cooling L.F. (1958). Tests on Full Scale Clay Flood Bank to Study Seepage 915 and the Effects of Overtopping. Building Research Station, Watford, Internal report No. $916 \quad$ C562.

917 18. Milly P., Wetherald R., Dunne K., Delworth T. (2002). Increasing risk of great floods in a $918 \quad$ changing climate. Nature, 415(6871), 514-517.

919 19. Morris M., Dyer M., Smith P., Falkingham J., Simms J. (2007). Management of Flood 920 Defences. Defra/EA, R\&D report FD2411, London. 
921 20. Munoz-Castelblanco J.A., Pereira J.M., Delage P., Cui Y.J. (2012a). The Influence of

922 Changes in Water Content on the Electrical Resistivity of a Natural Unsaturated Loess.

923 Geotechnical Testing Journal, 35(1): 11-17.

924 21. Munoz-Castelblanco J.A., Pereira J.M., Delage P., Cui Y.J. (2012b). The water retention 925 properties of a natural unsaturated loess from northern France. Geotechnique, 62, 95-106.

926 22. Perry J., Pedley M., Reid M. (2001). Infrastructure embankment: condition appraisal and 927 remedial treatment. CIRIA Report C550.

928 23. Rodriguez R., Sanchez M., Ledesma A., Lloret A. (2007) Experimental and numerical 929 analysis of desiccation of a mining waste. Canadian Geotechnical Journal, 44(6): 644$930 \quad 658$.

931 24. Shin H., Santamarina JC. (2011). Desiccation cracks in saturated fine-grained soils: 932 particle level phenomena and effective stress analysis. Geotechnique 61, 11, 961-972.

933

25. Smethurst J.A., Clarke D., Powrie W. (2012). Factors controlling the seasonal variation in 934 soil water content and pore water pressures within a lightly vegetated clay slope. Geotechnique, 62(5), 429-446.

936

26. Tang CS., Cui YJ., Shi B., Tang AM., Liu C. (2011). Desiccation and cracking behaviour 937 of clay layer from slurry state under wetting-drying cycles. Geoderma, 166: 111-118.

938

27. Utili S. (2013). Investigation by limit analysis on the stability of slopes with cracks. Geotechnique, 63(2), 140-154.

28. Xu C.Y., Singh V.P. (2001). Evaluation and generalization of temperature-based methods for calculating evaporation. Hydrological Processes, 15(2): 305-319.

29. Wan C.F., Fell R. (2004). Investigation of rate erosion of soils in embankment dams. J. of Geoenv. and Geotech. Engrg ASCE, 130, (4), 373-380.

944 30. Wu W. et al. (2011). Earthen embankment breaching. Journal of Hydraulic Engineering ASCE, 137, 1549-1564. 
946 31. Zhang Z., Tao M., Morvant M. (2005). Cohesive slope surface failure and evaluation. $J$ 947 Geotech \& Geoenv Engrg ASCE, 131, 898-906.

948 32. Zielinski M. (2009). Influence of desiccation fissuring on the stability of flood 949 embankments. PhD thesis, University of Strathclyde, Glasgow (UK).

950 33. Zielinski M., Sanchez M., Romero E., Sentenac P. (2011). Assessment of water retention 951 behaviour in compacted fills. Proc. ICE Geotechnical Engineering, 164, 139-148. 